\title{
El modelo de colonización antioqueña de James Parsons. Un balance historiográfico
}

\author{
Jaime Londoño \\ Universidad del Valle, Cali
}

Fecha de recepción: 15 de septiembre de 2002

Fecha de aceptación: 1 de octubre de 2002

\begin{abstract}
Resumen
Los procesos de colonización de vertiente de la región antioqueña colombiana desde finales de la Colonia no han sido estudiados detenidamente por la historiografía colombiana. Las pocas investigaciones que se han realizado se inspiran en la obra clásica de James Parsons, La colonización antioqueña en el occidente de Colombia, publicada en el país en 1949, cuya incidencia aún no ha sido plenamente evaluada. El único debate significativo se ha centrado en torno a la tesis de la conformación de una supuesta sociedad democrática e igualitaria de pequeños y medianos propietarios en la zona. Sin embargo, el autor señala que el modelo general de colonización propuesto por Parsons y el concepto de frontera que lo inspira, tomado de la obra de Frederick J. Turner, han sido apropiados por los investigadores de manera pasiva, sin someterlos a una verdadera revisión crítica. A través de un balance de las diferentes obras que, de una $\mathrm{u}$ otra manera, se han ocupado del tema de la colonización antioqueña, el autor trata de dar una respuesta acerca de las razones de esta apropiación pasiva del modelo parsoniano.
\end{abstract}

Palabras clave: COLONIZACIÓN ANTIOQUEÑA, JAMES PARSONS, FREDERICK J. TURNER, HISTORIOGRAFÍA COLOMBIANA, SIGLO XX, SIGLO XX.

\begin{abstract}
Colombian historiography has not studied in detail the colonization processes starting at the end of the Colonial period for the region of Antioquia in Colombia. The few available texts were inspired by James Parsons' classic study, La colonización antioqueña en el occidente de Colombia published in 1949, but its incidence has not been fully evaluated. The only significant debate has centered on the author's argument regarding the formation of a supposedly egalitarian society by the smallholders and mediumholders in the area. Nevertheless, this paper suggests that the general colonization model proposed by Parsons and the concept of frontier set forth, taken from Frederick J. Turner, have been appropriated by researchers in a passive manner without critically reviewing them. Through an evaluation of the different texts dealing with the topic of the antioqueño colonization, the author addresses the reasons for this passive appropriation of the Parsonian model.
\end{abstract}

Key words: ANTIOQUEÑO COLONIZATION, JAMES PARSONS, FREDERICK J. TURNER, COLOMBIAN HISTORIOGRAPHY, $19{ }^{\mathrm{TH}}$ CENTURY, $20{ }^{\mathrm{TH}}$ CENTURY.

Fronteras de la Historia 7 (2002)

(C) ICANH 
Historiador no es el que sabe, sino el que investiga, y, por tanto, el que discute las soluciones ya obtenidas y el que, cuando hace falta, revisa los antiguos procesos.

Lucien Febvre

La configuración espacial del norte del suroccidente colombiano, actuales territorios de los departamentos de Risaralda, Quindío y de las estribaciones de las cordilleras Central y Occidental en el departamento del Valle del Cauca, es producto de diversos procesos de poblamiento. Estos se inician 10000 años a.C. con la llegada de los primeros grupos de cazadores recolectores, continúan con el arribo de los españoles en el Siglo XVI y con los poblamientos interiores de los grupos mestizos durante el periodo colonial y finalizan con la colonización de vertiente acaecida en la región desde mediados del siglo XIX.

Estos procesos han sido estudiados con cierto detenimiento; sin embargo, la colonización de vertiente ha pasado desapercibida. Solamente se han efectuado análisis parciales sin profundizar en la especificidad del fenómeno. Casi en su totalidad, estas investigaciones están influidas por el modelo de colonización propuesto por James Parsons en su libro, La Colonización Antioqueña en el Occidente de Colombia ${ }^{1}$. La incidencia de esta obra no ha sido evaluada por la historiografía colombiana ${ }^{2}$, el único debate es el producido en torno a la tesis igualitaria, que origina la versión rosa de la colonización antioqueña: la conformación de una sociedad democrática de pequeños y medianos propietarios, planteamiento rechazado por diversos autores, quienes han subrayado la concentración de la tierra en pocas manos.

La obra de Parsons es la más representativa de un conjunto de trabajos, calificados como la versión positiva de los efectos de la frontera en Colombia. Este planteamiento, promulgado en las décadas de los años 30 y 40 del siglo pasado, fue defendido por la Federación Nacional de Cafeteros y por historiadores regionales y locales, quienes investigaron la ocupación e incorporación de los terrenos baldíos de los departamentos de Caldas, Risaralda, Quindío, norte del Tolima y norte del Valle del Cauca, considerando estos procesos como una "alternativa al conflicto". La abundancia de tierra libre y su disponibilidad ofrece a los campesinos la oportunidad de establecer fincas y mejorar su nivel de vida:

\footnotetext{
${ }^{1}$ La obra de Parsons fue publicada originalmente en 1949 por la Universidad de California, con el título, The Antioqueño Colonization in Western Colombia. En Colombia el libro fue traducido en 1949 por Emilio Robledo y editado en 1950, con el auspicio de la Dirección Departamental de Educación de Antioquia. Hasta la fecha el texto ha sido reeditado en cuatro ocasiones.

${ }^{2}$ Los únicos balances que existen sobre el tema son los siguientes: Jaime Jaramillo Uribe, "Visión sintética de la tarea investigativa desarrollada sobre la región antioqueña", en Moises Melo y FAES, eds., Los estudios regionales en Colombia: El caso de Antioquia (Medellín: Fundación Antioqueña para los Estudios Sociales - FAES -,Biblioteca Colombiana de Ciencias Sociales, 1982), 1-15; "El significado de la colonización antioqueña del occidente colombiano en el marco de la historia nacional" y Otto Morales Benítez, "La colonización antioqueña: Un Aspecto de la revolución económica de 1850", en Ficducal comp., La Colonización antioqueña (Manizales: Gobernación de Caldas, Biblioteca de autores caldenses, 1997), 23 e introducción, respectivamente.
} 
[...] contribuyendo a la prosperidad de la nación. La frontera significó una alternativa al predominio de grandes propiedades establecidas en tiempos coloniales; representó la posibilidad de una sociedad de clase media más estable y democrática $[\ldots]^{3}$.

El desarrollo de la economía cafetera, inseparablemente ligado al movimiento de colonización antioqueño, fue juzgado como responsable de la paz y de la prosperidad de la nueva nación. Una visión de conjunto de la literatura publicada sobre estos procesos denota el carácter repetitivo de los problemas abordados y un olvido del tema en la última década. Sí la historiografía, incluyendo la colombiana, experimentó en el siglo pasado un permanente proceso de transformación, tanto en el plano teórico como metodológico, es fundamental preguntarse: ¿Por qué en Colombia ha persistido el modelo de colonización propuesto por James Parsons? ¿Cómo la historiografía colombiana recibió y utilizó este modelo? La repuesta a estos interrogantes debe ajustarse al carácter secundario de la historiografía colombiana ${ }^{4}$ respecto a las grandes corrientes y escuelas historiográficas de primer nivel como son los Annales franceses, los historiadores marxistas ingleses, la cliometría norteamericana y recientemente la microhistoria italiana.

El carácter secundario de la historiografía colombiana se explica por la ausencia de comunidades académicas consolidadas y por la escasa reflexión en torno a la teoría de la historia. Esta carencia posibilita que en un alto porcentaje, los cambios y las innovaciones experimentadas en los temas, conceptos y métodos de la historiografía europea y norteamericana, guíe su producción. La ausencia de análisis historiográfico, definido como el estudio de la "producción escrita acerca de temas históricos" ${ }^{5}$ ", es el ejemplo más palpable de esta situación. Los trabajos publicados obedecen a iniciativas individuales ${ }^{6}$. Con pocas

\footnotetext{
${ }^{3}$ Catherine LeGrand, "Colonización y Violencia en Colombia: Perspectivas y Debate”, en Absalón Machado, comp., El Agro y la Cuestión Social (Bogotá: Tercer Mundo Editores/Banco Ganadero/Caja Agraria/Vecol, 1994), 6.

${ }^{4}$ La noción de historiografía colombiana hace alusión al "grupo heterogéneo" de historiadores profesionales, regularmente vinculados a universidades oficiales y privadas, a entes gubernamentales o a organizaciones no gubernamentales. Habitualmente, estas instituciones están radicadas en la capital del país y en las capitales departamentales. Desde sus orígenes, en la década del 60 del siglo XX, hasta el presente, se pueden identificar tres o cuatro generaciones de historiadores. Los miembros que integran este "grupo", no están unificados en torno a una comunidad académica consolidada o suficientemente estructurada a su respectivo paradigma. Por tanto, no tienen criterios claramente establecidos respecto a los temas de estudio, a los conceptos y a la metodología de investigación. La ausencia de líneas de trabajo unificadas se refleja en la existencia de tendencias de investigación de diversa índole, que no están necesariamente asociadas a paradigmas específicos. Por el contrario, en la mayoría de los casos el acercamiento se realiza de manera pragmática. Encontramos enfoques que oscilan desde el historicismo hasta las orientaciones más recientes de la historia cultural. Esta gama de tendencias es "renovada" de acuerdo a los cambios de la historiografía mundial.

${ }^{5}$ Josep Fontana, Historia. Análisis del pasado y proyecto social (Barcelona: Editorial Crítica, 1982), 9. Para una discusión más amplia sobre el tema véase Julio Aróstegui, La investigación histórica: teoría y método (Barcelona: Editorial Crítica, 1995), 18-27.

${ }^{6}$ La única excepción, es el estudio colectivo efectuado por los integrantes del Departamento de Historia de la Universidad Nacional, cuyos resultados están editados en el libro compilado por Bernardo Tovar Zambrano, $L a$
} 
excepciones, son un catálogo de reseñas de libros y de artículos, que no dejan una imagen clara de los desarrollos teóricos, metodológicos y temáticos de las diferentes historias sectoriales.

La relación de subordinación y dependencia de la historiografía colombiana obliga a plantear el análisis desde otras perspectivas, que respondan cómo los historiadores colombianos han recibido, adaptado, imitado, rechazado o cuestionado, los modelos analíticos europeos y norteamericanos. En este sentido, el concepto de apropiación, utilizado en estudios referentes a la historia de la educación en Colombia, posibilita un acercamiento diferente a estos problemas y permite superar el método de inventariar y catalogar por medio de reseñas la producción sobre un tema o una historia sectorial. Apropiar, según Olga Lucía Zuluaga, es:

[...] inscribir en la dinámica particular de una sociedad, cualquier producción técnica o de saber proveniente de otra cultura y generada en condiciones históricas particulares. Apropiar evoca modelar, adecuar, retomar, coger, utilizar, para insertar en un proceso donde lo apropiado se recompone porque entra en una lógica diferente de funcionamiento. Apropiar un saber es hacerlo entrar en las coordenadas de la práctica social. Es, por tanto, un proceso que pertenece al orden del saber como espacio donde el conocimiento está accionado por mecanismos de poder y no por la lógica del movimiento de los conceptos en el conocimiento científico. Sin embargo, para historiar un saber apropiado es necesario tomar un campo de conceptos más amplio que el apropiado con el fin de localizar los recortes, exclusiones, adecuaciones y amalgamas que conlleva tal proceso de institucionalización de ese saber?

Este concepto modifica el interrogante planteado inicialmente. La nueva pregunta debe indagar, ¿Cómo la historiografía colombiana se apropió (recibió, adecuó y aplicó) el modelo de colonización propuesto por James Parsons?

La respuesta es poco alentadora. La apropiación del modelo de colonización propuesto por Parsons puede definirse de pasiva. Su aplicación puede catalogarse de mecánica. Este planteamiento se fundamenta en dos razones. La primera, producto del olvido o, mejor, de no tener en cuenta en el diseño de las investigaciones el concepto articulador (frontera) de la obra del geógrafo norteamericano. Esta noción no es explícita en el texto de Parsons; es implícita y está asociada con la propuesta esbozada por Frederick Jackson Turner para analizar el caso del desplazamiento hacia el Oeste en los Estados Unidos.

El olvido, el desconocimiento, el no tener en cuenta este concepto, impidió a los historiadores colombianos apropiarse directamente de una categoría para el análisis de determinados procesos

Historia al Final del Milenio. Ensayos de Historiografia Colombiana y Latinoamericana, 2 vol. (Bogotá: Editorial Universidad Nacional, 1994).

${ }^{7}$ Javier Saenz Obregón, Oscar Saldarriaga y Armando Ospina, Mirar la infancia: Pedagogía, Moral y Modernidad en Colombia, 1903-1946 (Medellín: COLCIENCIAS/Foro Nacional por Colombia/Ediciones Universidad de los Andes/Editorial Universidad de Antioquia, 1997), XIV. 
históricos. En su lugar se produjo una apropiación indirecta y mecánica, mediada por la lectura y aplicación de la propuesta de Turner efectuada por James Parsons. La historiografía colombiana no se apropió de un concepto sino de un modelo. Desde el punto de vista de la información, este modelo estaba casi terminado, faltaba delinear algunos aspectos del proceso, específicamente los apartes dedicados a los actuales territorios de Risaralda, Quindío y las estribaciones de la cordilleras Central y Occidental en el Valle del Cauca, tarea que debía terminarse con investigaciones orientadas a rellenar estos vacíos.

Los historiadores colombianos tampoco detectaron un inconveniente adicional en el modelo, Parsons se inspira en la concepción turneriana de frontera, pero hace equivalente esta noción con la de colonización. Esta superposición contrarresta la capacidad interpretativa y explicativa de estos conceptos y reduce los estudios de frontera a la ocupación e incorporación de los espacios vacíos o no integrados. De esta forma, la frontera:

[...] aparece como un espacio vacío, como una "tierra virgen", y lo que interesa son las causas y mecanismos por los que se opera [su] ocupación, la consecuente puesta en explotación de esas tierras y el carácter de la sociedad que emerge de la misma $^{8}$.

La segunda razón, es la forma como los historiadores colombianos han utilizado el modelo. En su uso han omitido las "particularidades" de los procesos estudiados. De esta manera, la historiografía colombiana contribuyó a validar la idea de un proceso de colonización hegemónico, donde la ocupación e incorporación de las tierras baldías de los departamentos de Risaralda, Quindío y de las estribaciones cordilleranas en el departamento del Valle del Cauca es parte de la colonización antioqueña.

Es importante señalar un aspecto a favor de Parsons. Su propósito es claro: analizar la ocupación de nuevas tierras por parte de los antioqueños, y a pesar de las objeciones planteadas arriba, su modelo de colonización es lógico y responde a este objetivo. El único reparo es el no incorporar otros procesos de ocupación y colonización, que le posibilitaban construir un modelo más complejo. El problema para la historiografía colombiana es la aceptación de la propuesta de Parsons sin mayor discusión, localizando la polémica en un solo aspecto: el carácter igualitario o desigual de la sociedad que se estructura a partir de este proceso de colonización.

La apropiación indirecta, no de una categoría de análisis, sino de un modelo, impidió la recomposición, modulación y adecuación del concepto de frontera a las particularidades de los procesos históricos colombianos. De esta manera, se cerró la opción de buscar explicaciones alternativas. Las labores de investigación quedaron circunscritas a recabar información para superar las lagunas de la obra de Parsons y se obstruyó la posibilidad de participar y de contribuir en el debate teórico sobre la problemática del concepto de frontera. Al ser aceptadas

\footnotetext{
${ }^{8}$ Raul J. Mandrini, "Indios y Fronteras en el Area Pampeana (siglos XVI - XIX) Balance y Perspectivas", Anuario IEHS, 17 (1992): 62.
} 
las hipótesis planteadas por Parsons como verificadas ${ }^{9}$, su modelo de colonización fue aplicado mecánicamente, fue admitido como un molde cuya figura no admitía mayores reparos. Solamente debía superponerse y embutirle mecánicamente la información necesaria para llenarlo definitivamente. Por este motivo, las investigaciones subsiguientes presentan las mismas temáticas, repiten en gran medida la información utilizada por sus antecesores, consultan las mismas fuentes y no hay un esfuerzo por definir nuevos problemas. Los temas a indagar están dados de antemano, tanto para las investigaciones locales como regionales. Solamente hay que reunir los datos esenciales para continuar con la labor de llenar una matriz conocida previamente ${ }^{10}$.

La aplicación de estas premisas a los estudios relativos a la frontera del norte del Suroccidente colombiano ha reducido las labores de investigación a rutinas mecánicas. La repetición reiterada de esta práctica ha hecho invisible las particularidades de los procesos analizados. Así por ejemplo, la llegada de colonos de diferentes regiones del país, la participación de los empresarios caucanos y las políticas de colonización, efectuadas por las elites del Gran Cauca en el siglo XIX y por los dirigentes del Valle del Cauca en el siglo XX, no han abierto la opción de plantear nuevos problemas y de formular otras temáticas de análisis.

\section{La obra de James Parsons y la colonización de Risaralda, Quindío y el Valle del Cauca.}

La obra de James Parsons está asociada a su tesis doctoral. El tema inicial era la "adaptación humana al medio tropical montañoso". Por insinuación del profesor Carl Sauer, de la Universidad de California, decidió realizar su trabajo de campo en los Andes colombianos, prestando especial atención a la "industria cafetera en todas sus ramas". Al conocer la región antioqueña y su área de influencia, determinó centrar su interés "en el proceso de ocupación de las nuevas tierras", específicamente en la agricultura, la minería, el comercio, los caminos, la fundación de pueblos, la demografía y el proceso de industrialización del valle de Aburra ${ }^{11}$.

Como se reseño atrás, en el estudio del proceso de ocupación de nuevas tierras, Parsons se inspira en el modelo de frontera propuesto por Frederick Jackson Turner para estudiar el caso de los Estados Unidos, pero hace equivalente este concepto con el de colonización. Para Turner, el

\footnotetext{
${ }^{9}$ La única excepción es el debate en torno a la hipótesis referente al carácter igualitario de la colonización antioqueña.

${ }^{10}$ Estos planteamientos conducen a dos interrogantes: ¿Cuáles son las premisas epistemológicas que han regido y rigen el quehacer de los historiadores colombianos? ¿Cómo se han apropiado los historiadores colombianos de los postulados teóricos, metodológicos y temáticos de las grandes corrientes y escuelas historiográficas mundiales? La respuesta de ambas preguntas escapa a los objetivos de este trabajo y, por tanto, no será abordada en los acápites siguientes.

${ }^{11}$ James Parsons, "Reminiscencias sobre 'la colonización antioqueña”, en Ficducal, La colonización, 12, 15, 16. Véase además el prefacio del autor a la tercera edición de La colonización antioqueña en el occidente de Colombia (Bogotá: Carlos Valencia Editores, 1979), 9 -14.
} 
elemento más importante de la frontera americana es el hecho de que va por el límite de las tierras abiertas a la expansión: "[...] consideramos toda la faja fronteriza, incluyendo al país habitado por los indios y el margen externo del "área colonizada" ${ }^{2}$. Desde esta perspectiva, la frontera es la "línea móvil que señala el límite de la colonización con la naturaleza salvaje, sin conquistar" $"$.

Turner califica el término de elástico y considera que no necesita de una definición precisa debido al objetivo central de su reflexión: analizar el significado de la frontera para la historia de los Estados Unidos. Por este motivo, mantuvo a lo largo de sus obras lo que Richard Hofstadter a denominado como la "imprecisión de los términos fundamentales", la utilización del concepto de frontera con diversos sentidos: "ambiente desértico, tierra vacía y no colonizada, proceso social de colonización y americanización, población que vivía en cierta región, 'el Oeste' en sentido general", los recursos naturales que existían en estas tierras; en algunas ocasiones, recurrió a la definición utilizada por los funcionarios del censo, "la zona marginal de las colonias que tienen una densidad de dos habitantes o más por milla cuadrada" ${ }^{\text {" }}$. Para Alistair Hennessy, Turner utiliza este concepto en tres sentidos, como una región geográfica, en calidad de proceso de adaptación y como la existencia al borde de la colonización de un área de tierra sin utilizar, sin incorporar o sin colonizar ${ }^{15}$.

A pesar de la "imprecisión de los términos fundamentales", Turner relaciona el avance de la frontera norteamericana a la existencia de una zona de tierras libres que podía ser ocupada. La apropiación de esta zona, el corrimiento hacia el Oeste, se efectuó por diferentes rutas; en este proceso, el desplazamiento (cambio) de la frontera, el avance de la línea móvil, es producto de las labores de colonización, actividades que posibilitan la ocupación e incorporación de las tierras libres.

Al equiparar Parsons los conceptos de frontera y de colonización, su modelo explicativo queda reducido al estudio de las rutas seguidas por los antioqueños en el proceso de ocupación de la zona de tierras libres, situadas en los márgenes de los poblamientos coloniales; ocupación, efectuada mediante las actividades de colonización. La información empírica de Parsons y, ante todo, la visión de sus principales informantes: Emilio Robledo, Luis Ospina Vázquez, Gabriel Arango Mejía y, en el caso del Quindío, Luis Arango Cano, intelectuales comprometidos con la defensa del mito paisa ${ }^{16}$; se ajusta perfectamente al modelo de Turner. De esta manera, este

\footnotetext{
12 Frederick J. Turner, "El Significado de la frontera en la historia americana", en La frontera en la historia americana (San José: Universidad Autónoma de Centro América, 1986), 25.

${ }^{13}$ Turner, "La primera frontera oficial de la bahía de Massachusetts", Ibídem, 63.

${ }^{14}$ Richard Hofstadter, Los historiadores progresistas (Buenos Aires: Editorial Paidós, 1970), 124.

${ }^{15}$ Alistair Hennessy, The frontier in Latin American history (Albuquerque: University the New Mexico Press, 1978), 16

${ }^{16}$ Parsons, La colonizacion, (1989), 13-15. “Acompañe a don Luis [Ospina Vázquez] en visitas a fincas de su propiedad y de su familia en Yolombó, Fredonia y Venicia, donde me enseñó en "lo que quiere decir a ser un antioqueño". Nunca he tenido mejor guía y consultor". El mito paisa o antioqueño, se funda en la superioridad de la raza antioqueña, hombres emprendedores y amantes del trabajo, mujeres católicas, laboriosas y fecundas; cualidades que los hacen diferentes al resto de los colombianos.
} 
modelo queda en calidad de soporte implícito de la tesis doctoral de Parsons y posteriormente del libro editado con base en este trabajo.

El concepto de colonización en el título del libro, preocupó a Emilio Robledo ${ }^{17}$, quien consideró que podía ser mal interpretado por personas que veían con "malos ojos la preponderancia que ha alcanzado en pueblo antioqueño en varias actividades". No obstante, con base en la definición que aparece en el Diccionario de la Real Academia Española de los términos colonia y colono: "gente que se establece en un territorio inculto del mismo país, para poblarlo y cultivarlo [...] labrador que cultiva y labra una heredad por arrendamiento y suele vivir en ella"; se decidió conservar el título original del estudio, con el convencimiento de que su lectura demuestra que "el antioqueño se ha establecido en un vasto territorio del occidente de Colombia y lo ha poblado y cultivado" $"$.

Durante los siete meses que duró su investigación, Parsons no pudo contrastar sus datos de archivo y la versión de sus informantes con otros puntos de vista que le permitieran matizar sus hipótesis. Esta labor era difícil en la época. A mediados del siglo XX (1946) no existían historiadores profesionales en Colombia; apenas si se conocía literatura sobre el tema. Los únicos libros eran las monografías locales realizadas por participantes de la colonización, por descendientes de los mismos y por intelectuales locales y regionales, que resaltaban el papel de los antioqueños en el proceso.

La imposibilidad de compulsar la información de sus informantes con datos de archivo, condicionó la descripción efectuada por Parsons de la ocupación de nuevas tierras por parte de los antioqueños, al esbozo de una ruta de colonización que se desplaza en un solo sentido. Su punto de partida está ubicado en "los valles del río Negro"; los primeros pobladores son aventureros o vecinos de Rionegro y del valle de San José de Marinilla. De aquí, la línea de colonización se desplaza paulatinamente hacia el sur inicialmente por los flancos de las cordilleras central y posteriormente por las estribaciones de la cordillera Occidental.

Con el avance hacia el sur por la cordillera Central se inicia la fundación de nuevos poblados: Sonsón, Abejorral, Aguadas, Pácora, Salamina, Aranzazu, Neira y Manizales entre otras poblaciones. En este punto, los colonizadores penetran los territorios del Gran Cauca y continúa la oleada de fundación en los actuales territorios de los departamentos de Risaralda y el Quindío. Finalmente, la incorporación de nuevas tierras se realizó en las estribaciones cordilleranas del Valle del Cauca, donde finalizó el proceso ${ }^{19}$.

\footnotetext{
${ }^{17}$ Emilio Robledo fue el traductor y principal gestor de la publicación de la primera edición de la obra en castellano. Es reconocido como uno de los intelectuales más importantes de la elite antioqueña a mediados del presente siglo; fue miembro de las academias colombianas y reales academias españolas de la historia y la lengua. Durante algunos años fue presidente de la Academia Antioqueña de Historia.

${ }^{18}$ Parsons, Ibídem, 15. Véase además el prólogo de Emilio Robledo a la primera edición de La colonización antioqueña en el occidente de Colombia, 2da ed., (Bogotá: Banco de la República, 1961), 12, 13.

${ }^{19}$ Parsons, Ibídem, (1997), 21, 22, 114-134. Los colonizadores antioqueños también se desplazaron hacia el sur por el flanco oriental de la cordillera Central, de este proceso se destaca la fundación del Líbano y Roncesvalles en el Departamento del Tolima.
} 
La ocupación de la cordillera Occidental y sus zonas aledañas recibió un tratamiento similar al anterior. Parsons describe sumariamente la ocupación del territorio y reseña la fundación de nuevos poblados. Los primeros colonizadores del Occidente arribaron procedentes de Medellín y Amagá; posteriormente, con el desplazamiento del flujo colonizador hacia el Suroccidente, la procedencia se amplió considerablemente. Venían de diferentes zonas de Antioquia; muchos de las áreas de colonización de la cordillera Central, pasaban el río Cauca y en la zona de Riosucio, Supía y Marmato, se mezclaban con los indígenas y seguían impulsando el desplazamiento hacia el sur. Anserma, refundada en 1872, fue el núcleo propulsor de la colonización en los territorios del Gran Cauca. La incorporación de las nuevas tierras se extendió hasta los farallones de Cali. Parsons reconoce que existen otras zonas de emigración de antioqueños, "hacia el Chocó, las tierras del Sinú y el valle del río Nus; pero la región tradicional de colonización antioqueña continúa siendo hacia el sur" ${ }^{\prime 20}$.

La descripción realizada por Parsons de la colonización antioqueña presenta cierta riqueza de información en los apartes dedicados a este proceso en Antioquia. A medida que la ruta colonizadora se desplaza hacia el sur y se interna en las tierras del Gran Cauca el relato pierde calidad y se diluye en detalles y en datos aislados sin mayores contextos. Para la colonización del actual territorio del departamento de Risaralda, Parsons realiza descripciones generales de los procesos de ocupación de estas tierras, en los que sobresale la fundación de algunas poblaciones: Pueblorrico, Apía, Santuario, Balboa, Pereira, San Francisco, (actualmente Chinchiná), Santa Rosa de Cabal y Palestina. Reseña la concesión de terrenos baldíos por parte del Estado a los nuevos pobladores, especialmente a los de Santa Rosa de Cabal y resalta la "actitud hostil de los residentes de Cartago hacia estos antioqueños intrusos, locuaces y vigorosos" $"$.

En la colonización del Quindío, Parsons solamente enuncia las cuatro causas que propiciaron la llegada de los antioqueños a estos territorios: la existencia de árboles de caucho, la presencia de oro en los sepulcros indígenas, el alto precio de los cerdos y las ventajas ofrecidas por la región para huir o refugiarse de los efectos de las guerras civiles. Adicionalmente, expone en la nota de pie de página \# 37, una quinta causa que no desarrolla: la presión de los prestamistas y gamonales de Rionegro contra los emigrantes. Asimismo, reseña someramente el litigio de los colonos contra la Compañía Burila y asocia la fundación de los nuevos poblados, con excepción de los del norte, donde predominó "una especie de comunidad socialista", a una iniciativa empresarial, "provechosa para unos pocos terratenientes",2.

Para la colonización en el Departamento del Valle del Cauca, Parsons únicamente efectúa tres menciones: la primera, relaciona a Heraclio Uribe en calidad de fundador de Sevilla y defensor de los colonos ante las pretensiones de la Compañía Burila; la segunda, está referida al empuje efectuado hacia el sur por los colonizadores de la cordillera Occidental, evitando las tierras

\footnotetext{
${ }^{20}$ Ibídem, 28 y 136-140.

${ }^{21}$ Ibídem, 123-126 y 140, 141.

${ }^{22}$ Ibídem, 127-134.
} 
calientes del Valle de Risaralda, hecho que asocia con la fundación de varios pueblos: Versalles, Trujillo, Darién, Restrepo, El Cairo, Albán, El Aguila, etc.; la tercera, reseña la construcción del puente sobre el río Riofrío y la apertura del camino a Trujillo, obras que favorecieron la ocupación del alto Calima, especialmente el territorio de los actuales municipios de la Cumbre y Bitaco $^{23}$.

Estos vacíos aunados al desconocimiento del concepto articulador de la obra de Parsons, la noción de frontera propuesta por Frederick Jackson Turner, posibilitó que los historiadores colombianos se apropiaron únicamente de los aspectos temáticos y metodológicos del modelo propuesto. Los objetivos y alcances de las nuevas investigaciones fueron reducidos o se enfocaron solamente, tanto en el plano regional como local, a completar los vacíos dejados en sus descripciones, logrando en algunos casos relatos más acabados de estos procesos, pero sin articular hipótesis explicativas. El carácter repetitivo de estos estudios y el desplazamiento de la historiografía colombiana hacia otros temas de moda, explica el relativo abandono de esta temática en los últimos años.

\section{La apropiación de la obra de James Parsons por la historiografía colombiana}

¿De qué manera la historiografía colombiana se apropió del modelo de colonización propuesto por James Parsons? Para responder este interrogante se ha dividido la literatura sobre el tema en dos bloques: el primero concierne a los defensores - continuadores de la obra, el segundo, a los críticos - continuadores y a algunos revisionistas del modelo parsoniano. Es difícil ordenar los trabajos de cada bloque en tipologías específicas. Esta dificultad estriba en la ausencia de "comunidades académicas" orientadoras de las labores de investigación. En su lugar, se encuentran iniciativas individuales, en algunos casos financiadas por empresas privadas o instituciones estatales, que se traducen en la repetición de las temáticas de investigación, en la carencia de debates historiográficos y en la ausencia de nuevos problemas.

La literatura referente a los procesos de colonización en los departamentos de Caldas, Risaralda, Quindío y el Valle del Cauca es muy desigual. Por este motivo se realizará una caracterización general de los escritos que integran cada bloque. En esta agrupación se han dejado al margen las monografías locales de corte "tradicional", generalmente escritas por políticos, maestros, intelectuales y notables de los pueblos que se fundan en los procesos de frontera del norte del Suroccidente colombiano.

Los defensores - continuadores de Parsons se pueden agrupar en dos grupos. El primero corresponde a investigadores interesados en los procesos de poblamiento en Colombia, quienes utilizan a Parsons como fuente de primera mano para sus estudios. También hacen parte de este grupo, los historiadores regionales y locales que intentan completar, consciente o

\footnotetext{
${ }^{23}$ Ibídem, 131, 134 y 141.
} 
inconscientemente, las descripciones del autor. El segundo grupo, los integran investigadores interesados en temáticas diferentes a los procesos de ocupación de nuevas tierras. Sus objetos de estudio están enfocados hacia la violencia, la subordinación campesina, las formas de urbanización y la economía cafetera. Estas cuestiones los obligan a referirse a los procesos colonización sin profundizar en sus particularidades, solamente como marco de referencia para sus investigaciones.

En los trabajos regionales y locales, Parsons se convierte en fuente obligatoria; su modelo es utilizado de forma implícita y en pocos estudios explícitamente. Como estos autores no están interesados en investigar sobre los procesos de colonización, aceptan las tesis existentes. El resultado de este esfuerzo, se palpa en versiones más acabadas de este proceso de colonización, con el aporte de nueva evidencia empírica y, en obras con argumentos muy generales, débilmente sustentados. Para una mejor comprensión estos trabajos se han dividido en tres unidades: la primera, agrupa los estudios relacionados con la violencia; la segunda, reúne la obra de Jacques Aprile; y la tercera unidad, la menos homogénea, recoge estudios de diferente orden.

La apropiación pasiva del modelo de Parsons por parte de los defensores - continuadores no oculta los aportes efectuados por estos investigadores al estudio de los procesos de frontera en Colombia. De forma general podemos identificar tres contribuciones. La primera es la división de la colonización antioqueña en varias etapas. En lo que atañe al departamento del Valle del Cauca, se plantea el concepto de colonización antioqueña tardía. La segunda contribución está asociada al descubrimiento de nueva información; datos utilizados para terminar de llenar las lagunas presentadas por el modelo parsoniano. La tercera contribución es la interpretación de estos procesos a partir de los conceptos de colonización espontánea, empresarial y oficial.

En el bloque de críticos - continuadores de Parsons se agrupan trabajos referentes al poblamiento en Colombia, al análisis de la economía cafetera y algunos estudio regionales. La mayoría de estos escritos tienen un elemento en común. Controvierten la tesis de la versión rosa de la colonización antioqueña: "la conformación de una sociedad democrática de pequeños y medianos propietarios", pero aceptan el modelo de colonización propuesto. En los últimos años se han publicado varios escritos de corte regional y local que cuestionan la hegemonía de los antioqueños en los procesos de colonización de Risaralda, Quindío y el Valle del Cauca. Estos autores han identificado la presencia de colonos de diferentes regiones del país y destacan los proyectos estatales y empresariales liderados por las elites del Gran Cauca. Sin embargo, esta literatura, que podemos calificar de revisionista, tiene un carácter ambiguo y marginal, su circulación es restringida y aún no hace mella en las grandes explicaciones de la historiografía colombiana.

Los críticos del modelo parsoniano, no plantean un concepto explícito de frontera. Sus investigaciones están guiadas por la noción de Frederick Jackson Turner, posiblemente apropiada indirectamente de Parsons y, por tanto, aplicada mecánicamente. De esta manera, sus obras contribuyen a perpetuar las hipótesis del geógrafo norteamericano. La controversia de 
estos investigadores está acentuada en la estructura de propiedad derivada de estos procesos de colonización. No obstante, la documentación revisada para plantear la tesis de la concentración de las tierras baldías en pocas manos puede calificarse de parcial o incompleta. La fuente utilizada es el registro de adjudicación de tierras públicas, documento que no recoge la dinámica de la evolución de la propiedad privada en las zonas de frontera. De cara al futuro están pendientes monografías que aborden esta problemática con base en los registros notariales.

En la literatura calificada de revisionista tampoco se percibe un concepto de frontera. Estos autores comparten la crítica de la versión rosa de la colonización antioqueña e intentan alejarse del modelo de Parsons, objetivo conseguido parcialmente. La falta de una noción de frontera alternativa a la de Turner, les impide articular hipótesis que refuten totalmente el arquetipo parsoniano. La información plasmada en estos escritos controvierte el carácter hegemónico de los antioqueños en la colonización del norte del Suroccidente colombiano, pero no es utilizada en la elaboración de un modelo diferente del proceso de ocupación e incorporación de estos territorios.

En conjunto estos aportes representan un esfuerzo de completar el modelo de Parsons. La información que aportan estos trabajos puede ser re-interpretada y matizada a la luz de nuevos problemas y de nuevos conceptos de frontera. Muchos de los datos utilizados para terminar el modelo parsoniano, cuestionan la validez de este arquetipo, pero los investigadores no parecen percatarse de ello. Su tarea se limita a rellenar el molde con la nueva información. La noción de hipótesis verificada y no digna de ser revisada les impide una actitud crítica en sus trabajos intelectuales.

En los acápites siguientes vamos a sustentar estos planteamientos. Para ello analizaremos una serie de trabajos que ilustran las obras más representativas, tanto de los defensores continuadores como de los críticos - continuadores de la obra de Parsons.

\section{A. Los defensores - continuadores}

\section{Los estudios sobre la colonización antioqueña y el poblamiento en Colombia}

Alvaro López Toro, con base en literatura secundaria, explica el cambio socioeconómico experimentado por Antioquia en el siglo XIX. Como hipótesis propone la interdependencia de dos factores: el primero está asociado a los efectos de la colonización antioqueña hacia el sudoeste y hacia el sur; el segundo, es el advenimiento de un grupo de mineros, comerciantes, empresarios e industriales que lideró e innovó el crecimiento y las transformaciones de la economía regional ${ }^{24}$. El autor admite el modelo de colonización de Parsons, pero no reconstruye

\footnotetext{
24 “Migración y cambio social en Antioquia durante el siglo XIX”, en Alvaro López Toro, Ensayos sobre Demografia y Economía (Bogotá: Banco de la República, 1991), 471, 472.
} 
las rutas de ocupación, las acepta en calidad de verificadas y propone una explicación general de las consecuencias de la incorporación de nuevas tierras sobre la economía antioqueña. En el escrito, los procesos de frontera y de colonización de los territorios del norte del Suroccidente colombiano son mencionados fugazmente, casi siempre en las notas de píe de página, particularidad que le resta valor al artículo para los efectos del presente balance.

Las menciones fugaces a los territorios del norte del Suroccidente colombiano no son obstáculo para calificar a López Toro como defensor - continuador de Parsons, pues acepta sin reparos el modelo de colonización del geógrafo norteamericano. Sin embargo, la importancia del artículo reside en la apertura de nuevas perspectivas analíticas, varias de ellas retomadas por otros autores $^{25}$. Como ejemplos, podemos citar: 1) el problema de las causas de la inmigración de los antioqueños hacia las áreas de colonización ${ }^{26}$; 2) la tipología de las zonas ocupadas por los colonizadores procedentes de Antioquia y el tipo de colonización que ocurrió en cada una de ellas; 3) la dinámica económica del proceso colonizador y 4) las comparaciones con la frontera norteamericana y latinoamericana, recurso que permite situar el caso antioqueño en una perspectiva más amplia.

Roberto Luis Jaramillo construye un relato más rico en detalles que la obra de James Parsons ${ }^{27}$. No se aleja del modelo propuesto acepta la existencia de un macroproceso de colonización orientado hacia el Sur, pero dividido en varios subprocesos, que posibilitan una versión más acabada de la incorporación de los actuales territorios de los departamentos de Risaralda, Quindío y el Valle del Cauca. En su escrito subyace el concepto de frontera de Turner, una línea "móvil y progresiva" que variaba de acuerdo al avance de los colonizadores antioqueños.

En el territorio del departamento de Risaralda, Jaramillo divide el proceso de colonización antioqueño en dos. El primero comprende la zona entre Manizales y Cartago. En el relato, reseña el cambio de nombre del río Chinchiná realizado por Agustín Codazzi, por solicitud del gobierno de Antioquia, que pretendía controlar la aldea la María, perteneciente al Gran Cauca y de filiación liberal. Menciona la ocupación de estas tierras realizada por colonos antioqueños, quienes huían de la presión de la sociedad colonizadora "González Salazar y Cía" y pretendían instalarse en las cien leguas de tierras baldías existentes en la jurisdicción del cantón de Cartago. En este punto, sobresale la figura de Fermín López y su clan familiar, quienes partieron desde su rocería en San Cancio, hoy Manizales, atraviesan la selva y llegan a Cartago. El segundo subproceso, comprende parte del actual departamento de Risaralda y el occidente del departamento de Caldas. En el siglo XIX este territorio era parte de la jurisdicción del cantón de Supía, ente político - administrativo que pertenecía al Gran Cauca. Contaba con quince leguas de terrenos baldíos y varias poblaciones habitadas por indígenas, negros y mulatos, factores que dificultaban la colonización. En esta zona, los antioqueños "solo

\footnotetext{
${ }^{25}$ Por motivos de espacio no podemos analizar como la propuesta de López Toro ha sido desarrollada en otras investigaciones.

${ }^{26}$ En este aspecto López Toro recupera de manera implícita la noción de válvula de seguridad planteada por Turner.

${ }^{27}$ Roberto Luis Jaramillo, "La colonización antioqueña", en Jorge Orlando Melo, director general, La historia de Antioquia, 2 edición (Medellín: Editorial Presencia, 1991).
} 
recolonizaron terrenos abandonados $[\ldots]$ y repoblaron caseríos decadentes, que revitalizaron e integraron a la economía antioqueña". De igual forma, el autor asocia el desarrollo del "comercio, la minería, la agricultura, las artes y las ciencias" en estas zonas, a la llegada del flujo de antioqueños ${ }^{28}$.

El subproceso del Quindío recibe un tratamiento diferente por parte de Jaramillo. No se ocupa de describir el proceso de ocupación e incorporación del territorio y solamente enuncia las causas que motivaron la llegada de los colonizadores. Para Jaramillo, el fracaso de las autoridades caucanas de establecer una colonia antioqueña en jurisdicción de la ciudad de Cartago, es fruto de su política "avara y errática" respecto a la adjudicación de baldíos. Como alternativa, el gobierno del Cauca creó la colonia penal de Boquía, cuyos presos estaban destinados a apertura del camino Cartago - Ibagué, a la que se le unieron varios antioqueños, originando la población de Salento. Este poblado, junto a Pereira y Santa Rosa de Cabal sirvió de trampolín para que "un impresionante contingente de colonos antioqueños" saliera a "poblar, repoblar, o fundar" en esta subregión del Gran Cauca.

Jaramillo se aleja de las cuatro causas que arguye Parsons para explicar la colonización del Quindío. Propone como el factor principal la existencia de cien leguas de terrenos baldíos, además,

[...] de las otras muchas leguas de tierras templadas y frías prácticamente despobladas, pertenecientes a los antiguos cantones de Anserma, Tuluá, Buga, Palmira, etc., sin olvidar el atractivo del contrabando, es también conveniente agregar que parte del éxito logrado por los antioqueños se debió a un ejercicio propio de la agricultura, muy distinta a la caucana ${ }^{29}$.

En el caso de la colonización del departamento del Valle del Cauca, Jaramillo reseña el flujo de antioqueños y, en menor medida, de boyacenses y santandereanos. Estos colonizadores avanzaron por la cordillera Occidental hasta los farallones de Cali y por la cordillera Central hasta la parte alta del municipio de Florida, donde fueron detenidos por indígenas Caucanos. De la misma forma, reseña las actividades empresariales de la familia Caicedo con los terrenos de la Hacienda de la Paila. Estas operaciones comprenden la creación de la "Compañía de Fomento de la Paila", un contrato de administración de dicha propiedad con Tomás y Julián Uribe Toro y la conformación en 1884 de la "Empresa Burila". Para Jaramillo, la fundación de Sevilla y posteriormente de Caicedonia es producto de estas actividades ${ }^{30}$.

Aunque Eduardo Santa comparte el modelo de Parsons, se diferencia en dos matices, que no alteran ni completan las descripciones realizadas ${ }^{31}$. En este sentido, su obra puede considerarse como una visión apologética que, de acuerdo a la fecha de publicación (1993), denota un paso

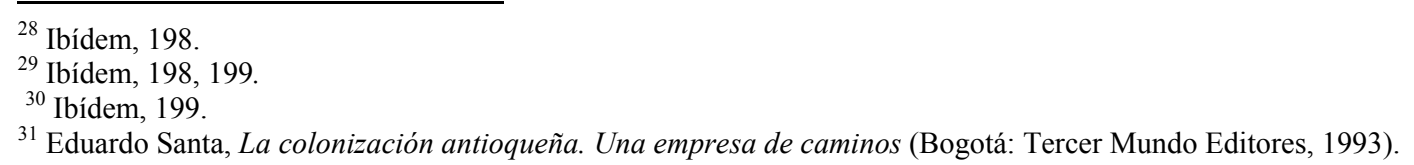


atrás en las actividades de investigación sobre este proceso. El primer matiz es el carácter épico. La colonización antioqueña es definida como una "empresa comunitaria": "la única revolución efectiva en el campo social y económico de la república". Es la mayor gesta del siglo XIX, realizada por

[...] gentes resueltas, emprendedoras y valientes hasta el propio heroísmo", continuadores de "la empresa de los conquistadores españoles, quizá con mayor fortuna que estos [...] a ese tenaz esfuerzo por construir la patria se debe la existencia de más de cien poblaciones grandes y pequeñas [...] hijas del siglo XIX y del hacha antioqueña $[\ldots]$ de esa epopeya nace un país nuevo y una nueva economía agrícola ${ }^{32}$.

El segundo matiz, define como una "empresa de caminos", tesis no verificada, enunciada y adornada con ribetes apologéticos:

[...] un largo camino con muchas variantes y ramificaciones, para todo el que quisiera y tuviera suficientes arrestos de hombría, pudiera seguirlo hasta el sitio donde no hubiera nadie en posesión de tierras y pudiera clavar allí las estacas de su rancho y escarbar la tierra fecunda [...] Los caminos, pues, fueron el presupuesto básico para el establecimiento de los desmontes y para la fundación de los pueblos $^{33}$.

Como "empresa de caminos" la colonización se inicia con Mon y Velarde. El primer pueblo fundado en la ruta hacia el sur fue Sonsón (1797), posteriormente la incorporación se produce en los departamentos de Caldas, Quindío y Risaralda. A continuación, los colonizadores penetraron a los departamentos del Tolima, siguieron al Valle del Cauca y luego al Cauca:

[...] esa gota de sangre trashumante y emprendedora sigue abriendo la brecha y hoy mismo continúa haciendo fundaciones en las selvas del Chocó, del Darién, del Caquetá y de los territorios nacionales ${ }^{34}$.

Santa esboza varias causas que propician el inicio de la colonización en el siglo XVIII:

[...] el espíritu aventurero propio de los antioqueños, estimulado por la pobreza del suelo nativo, por el crecimiento desmedido de las familias, por el afán de hacer riqueza $\mathrm{y}$, particularmente, por la búsqueda de tesoros indígenas o guaquerías y también por el fenómeno de contagio social que movilizó a grandes masas ${ }^{35}$.

\footnotetext{
${ }^{32}$ Ibídem, 17, 18.

${ }^{33}$ Ibídem.

${ }^{34}$ Ibídem

${ }^{35}$ Ibídem, 18, 19, 20, 30, 31.
} 
La colonización tiene cuatro etapas, una más que la propuesta realizada por Otto Morales Benítez en su libro Cátedra Caldense. Estas no alteran la unidad del proceso. Por el contrario la refuerzan, al cobijar las "complejidades", los "altibajos" y "modalidades" del fenómeno. La primera etapa, denominada colonial, corresponde a las postrimerías del siglo XVIII. Se inicia en 1785 con la llegada de Mon y Velarde y se extiende hasta principios del siglo XIX. La segunda, comprende la primera mitad del siglo XIX. El proceso de independencia detiene las políticas agrarias iniciadas por Mon y Velarde y solamente en 1821 se reactivan estas iniciativas, con pocas adjudicaciones de terrenos baldíos y con el fracaso de las disposiciones para atraer inmigrantes extranjeros. La tercera, definida como la "gran reforma agraria", comienza a mediados del siglo XIX y se extiende hasta 1880 . Se caracteriza por los esfuerzos de los gobiernos de turno para adjudicar los baldíos a las gentes sin tierra. La cuarta etapa comprende las dos últimas décadas del siglo XIX y las primeras del XX. En ella la colonización se hace más lenta y la escasez de tierras en la frontera sur, orienta la búsqueda de tierras hacia el Choco, Urabá y otros territorios. Paralelamente el llamado descuajador de montañas, cede terreno ante el caficultor y el ganadero ${ }^{36}$.

En la obra, la colonización del norte del Suroccidente colombiano está inmersa en las particularidades de esa empresa comunitaria y de caminos. Eduardo Santa solamente realiza menciones generales sobre este proceso, cita a Parsons para establecer las causas que originaron la colonización del Quindío y nombra algunos de los poblados que se fundan. En el segundo capítulo, dedica un acápite a la empresa Burila, sección plagada de imprecisiones y con una extensa cita de la novela histórica de Benjamín Baena Hoyos, El río corre hacia atrás. Finalmente, reproduce pasajes de la obra de autores costumbristas o viajeros extranjeros que pasaron por las montañas del Quindío ${ }^{37}$.

Fabio Zambrano y Olivier Bernard presentan "la evolución del proceso de poblamiento en el actual territorio colombiano a partir de la fundación de ciudades" 38 . Concretamente se preguntan cómo era la ocupación del espacio a medida que se fundaban núcleos urbanos y cómo evolucionaba la distribución de la población, según los diferentes procesos históricos. La respuesta es construida con un estudio de larga duración. En él se identifican dos periodos. En el primero o colonial, el eje de poblamiento se estructura en torno a la ciudad. Desde ella organiza la explotación de las regiones conquistadas y se administraban las unidades económicas. Los centros urbanos servían para estructurar el orden social promulgado por la corona española: la república de blancos y la república de indios ${ }^{39}$.

\footnotetext{
${ }^{36}$ Ibídem, 60-66. La cursiva es del autor.

${ }^{37}$ Ibídem, 19, 20, 21, 102-106, 121-218.

${ }^{38}$ Fabio Zambrano y Olivier Bernard, Ciudad y territorio. El proceso de poblamiento en Colombia (Bogotá: Academia de Historia de Bogotá/Instituto Francés de Estudios Andinos, 1993).

${ }^{39}$ Ibídem, 25-61.
} 
En el segundo periodo, denominado republicano, identifican tres variables, relacionadas con tres ciclos de poblamientos y asociados a etapas demográficas ${ }^{40}$. La primera variable es la recuperación demográfica del siglo XVIII. La segunda, son los ciclos económicos, ligados a la ocupación de las vertientes cordilleranas, motivada por el cultivo del café, su desplazamiento de la cordillera Oriental a la cordillera central y la industrialización. La tercera, "es el control de las epidemias y las enfermedades tropicales, logros científicos del siglo XX que estuvieron acompañados de avances en la higiene" ${ }^{, 41}$.

La ocupación del norte del Suroccidente colombiano hace parte del periodo republicano y es abordada en dos acápites titulados, "subregión montaña cafetera" y "subregión valle del Cauca". En la obra no hay citas del estudio de Parsons, pero los autores con base con algunos estudios regionales, siguen su modelo de colonización. Para ellos, la colonización de este territorio se inicia con el proceso de conquista, la fundación de Santa Ana de los Caballeros y la llegada de Alvaro de Mendoza a la hoya del Quindío. Luego continúa en el periodo colonial, pero solamente reseñan en este punto el establecimiento de asentamientos "ubicados en los márgenes de la subregión, como Marmato, Supía y Mistrató" ${ }^{22}$.

La colonización de los territorios de Caldas y del Quindío comienza a principios del siglo XIX y se extiende hasta el siglo XX. Fue realizada por colonos provenientes de Antioquia, quienes comenzaron su desplazamiento a finales del siglo XVIII, ante la presión de las concesiones realengas. La ocupación se realizó por medio de tres "corrientes migratorias" o "líneas de colonización". Los autores no establecen una diferencia sustantiva entre estos conceptos y tampoco precisan su significado. Estas "líneas" corresponden al modelo colonizador de Parsons. La primera corriente sigue las estribaciones de la cordillera Central. La segunda, siguió "el rumbo del antiguo camino que comunicaba a Antioquia con el Cauca", la tercera, "partió de los centros mineros de Marmato, Riosucio y Supía, siguió la banda occidental del río Cauca"43.

La "subregión Valle del Cauca" es analizada de forma similar a la "subregión montaña cafetera". Los autores estudian los procesos de poblamiento desde la conquista española, pasan por el periodo colonial y finalizan con la ocupación de las vertientes cordilleranas. Durante la dominación española se estructuró un eje de poblamiento en torno al río Cauca y sus tierras planas adyacentes, que era reforzado por el camino real que comunicaba a Lima, Quito, Santafé y Caracas. La manumisión, la abolición de resguardos indígenas, la consolidación del cultivo del café y la colonización antioqueña motivaron un cambio en el eje de poblamiento. Con esta modificación, se fundan, después de 1900, nuevas poblaciones. Lastimosamente los autores las ubican en su totalidad en la cordillera Occidental, olvidando la existencia de la cordillera

\footnotetext{
40 "Nos encontramos con el fenómeno de movimientos de población cada cien años, que los podemos asociar con la saturación demográfica de las regiones de clima frío que expulsó la población hacia tierras templadas, entre 17401780. Luego, en 1840-1860, el 80\% de la población de la Región Andina estaba en los climas fríos y templados y el desplazamiento favorece al clima medio. En 1940 -1960 comienza a reubicarse la población en clima frío, en un claro proceso de retorno poblacional”. Ibídem, 67.

${ }^{41}$ Ibídem, 67, 68

${ }^{42}$ Ibídem, 149

${ }^{43}$ Ibídem, 149, 150.
} 
Central. La nueva oleada de fundaciones generó conflictos agrarios y luchas de poder entre hacendados, comerciantes, funcionarios públicos y pobladores, que influyen en la violencia partidista de $1950^{44}$.

En el libro la hoya del Quindío tiene un "tratamiento especial". Los autores, con base en la obra de Jaime Lopera, La Colonización del Quindio, reseñan las causas que motivaron la colonización de este territorio. Estos móviles son los mismos que esgrime Parsons. Destacan la colonia penal de Boquía y la fundación de Salento como procesos de colonización estatal, diferente a la simple titulación de baldíos, con un propósito específico: "ampliar la frontera agrícola y [...] desarrollar el sistema vial [...] lo cual atrajo pobladores de diversos lugares del país". Zambrano y Bernard dedican unas pocas líneas a la economía resultante de estos procesos de colonización. La definen como una "economía de frontera", que se constituye en torno a una vida mercantil, ayuda a consolidar la red urbana y posibilita la vinculación del pequeño productor familiar con la fonda y el comercio de las ciudades. De esta manera, la diferenciación social iniciada con la colonización se profundiza. Desigualdad que se extiende a los centros urbanos. Los nuevos poblados se estructuran de forma piramidal, encontrándose Manizales en el vértice, ciudad que no pierde su hegemonía con la irrupción de la economía cafetera ${ }^{45}$.

Hermes Tovar Pinzón ${ }^{46}$, aborda los aspectos generales de la colonización de baldíos en el centro de Colombia a comienzos del Siglo XIX. Su libro está dividido en tres capítulos ${ }^{47}$. En el segundo realiza un breve análisis de la colonización en Santander y estudia la colonización antioqueña, proceso que califica como fundamental en la historia de Colombia. En su argumentación, sigue el modelo de colonización de Parsons, pero establece algunas diferencias con esta propuesta. La obra está orientada por un concepto de frontera: la "materialidad de los espacios marginales, incorporados a economías regionales, nacionales y mundiales, y como forjadores de leyendas y expresiones culturales propias"48. Esta noción, es manejada implícitamente; no obstante, la lectura deja una sensación diferente. El autor plantea el concepto en la introducción, pero desaparece del relato en el resto de la obra. La narración sigue un hilo conductor de corte cronológico que sirve de base para organizar la información seleccionada en cada uno de los temas y acápites que componen el texto. La "reflexión conceptual" está acompañada de una propuesta metodológica: la realización de estudios regionales en los futuros

\footnotetext{
${ }^{44}$ Ibídem, 160, 162. Los autores consideran que el poblamiento en la subregión del Valle del Cauca es más intenso que en la subregión montaña cafetera.

${ }^{45}$ Ibídem, 150, 151.

${ }^{46}$ Hermes Tovar Pinzón, Que nos tengan en cuenta. Colonos, empresarios y aldeas: Colombia, 1800-1900 (Bogotá: Colcultura, 1995).

${ }^{47}$ En el primer capítulo, analiza tres elementos "fundamentales para el proceso de colonización": 1) el crecimiento y la distribución de la población durante el siglo XIX; 2) un inventario de la forma como el Estado administró los terrenos baldíos e identifica las regiones "hacia donde marchó la población una vez que abandonó las altiplanicies andinas"; 3) un repaso de la legislación que reguló el derecho de la nación a conocer cuales eran sus baldíos y a disponer de ellos según convicciones, visiones e intereses de la clase política. En el tercer capítulo, "Las aldeas Como espacios para la Colonización en el Tolima", se analiza la "colonización a partir de aldeas en el departamento del Tolima".

${ }^{48}$ Ibídem, 15, 16
} 
trabajos sobre los procesos de frontera en Colombia, alternativa que algunos historiadores han planteado para otros periodos históricos y para otras historias sectoriales.

El concepto de frontera de Tovar está inspirado en la propuesta de Frederick Jackson Turner, de quien retoma la tesis referente al significado de la frontera para la democracia de los Estados Unidos $^{49}$. Sin embargo, matiza este planteamiento para Colombia:

[...] la frontera más que un paradigma de valores nacionales, esbozó las virtudes y los atributos de una sociedad regional que los redistribuyó entre los espacios ocupados y entre los inmigrantes que llegaban a las nuevas tierras, en un afán por consagrar sus aventuras, pero allí donde lo antioqueño no prevaleció, la colonización adquirió distintas dimensiones" ${ }^{, 50}$.

De acuerdo con las referencias bibliográficas, Tovar es el único de los autores analizados que lee los desarrollos de la teoría de frontera, aborda directamente el modelo de Turner y las alternativas analíticas al mismo, aunque no las tiene en cuenta, ¿Por qué no contempló estas opciones en su obra? La respuesta atañe exclusivamente al autor. Este comentario señala una de las debilidades más sentidas de la historiografía colombiana: la apatía frente a la reflexión teórica, indiferencia que resta calidad a muchos estudios.

La lectura de Turner, le posibilita a Tovar asumir el concepto de frontera, pero, al igual que Parsons, lo hace equivalente con el de colonización. De igual forma, no logra construir un modelo alternativo; por el contrario, acepta sin mayores críticas la propuesta y la ratifica con base en literatura secundaria, precisamente con las obras que se apropian pasiva y mecánicamente del modelo. De esta manera, Tovar se convierte en un continuador - defensor de Parsons.

Tovar asocia la ocupación de los territorios de los departamentos de Risaralda, Quindío y de las estribaciones de las cordilleras Central y Occidental en el Valle del Cauca a la colonización antioqueña; concretamente a dos rutas, las mismas que propone Parsons en su modelo. La primera parte de Rionegro para fundar Sonsón y Abejorral, desplazarse al sur del río Arma por las tierras de la concesión Aranzazu y fundar Salamina, Neira, Manizales y Pensilvania. Posteriormente se interna en el Gran Cauca. La segunda se inicia en los "centros mineros de Marmato, Riosucio y Supía". El desplazamiento de los colonos reanima la vida socioeconómica

\footnotetext{
49 “[...] El efecto más importante de la frontera ha sido haber fomentado la democracia aquí y en Europa [...] la frontera produce el individualismo [...] produce una antipatía contra toda forma de control en especial si es directo. [...] El individualismo de la frontera ha fomentado la democracia desde el principio [...] a pesar del medio ambiente, a pesar de la costumbre, cada frontera proporcionó ciertamente un nuevo campo de oportunidad, una puerta de escape de la esclavitud del pasado; y la frontera se ha visto acompañada por una frescura y una confianza y un desprecio por la vieja sociedad, junto con una impaciencia por librarse de sus imposiciones e ideas y una indiferencia ante sus enseñanzas. Lo que el mar mediterráneo fue para los griegos, rompiendo los lazos de costumbre, ofreciendo nuevas experiencias, dando lugar a nuevas instituciones y actividades eso fue la siempre movible frontera para los Estados Unidos [...]". Al respecto véase Turner, "El significado", 52 y 60.

${ }^{50}$ Ibídem, 16.
} 
de Anserma y genera la fundación de nuevos poblados: "Quinchía, Apía y Santuario. Cada uno de estas fundaciones atrajo a los colonos hacia una frontera que parecía inagotable" ${ }^{\text {. }}$.

A diferencia de otros autores, Tovar considera, con base en la obra de Catherine LeGrand, Colonización y Protesta Campesina en Colombia ${ }^{52}$, que la colonización antioqueña no fue el único proceso de poblamiento experimentado por la sociedad colombiana del siglo XIX. La ocupación de nuevas tierras afectó todas las regiones de Colombia. No se trató de un "proceso uniforme sino que se transformaba a medida que la población avanzaba, tanto por las cordilleras y selvas como por las planicies y vertientes". La divergencia radica en la forma de participación de algunos empresarios territoriales:

Unos pretendieron controlar a los colonos fundando pueblos; otros actuaron contra las aldeas y otros disputaron los espacios a los cultivadores primitivos. Algunos más vendieron parcelas y valorizaron la frontera al fundar economías de subsistencia y fortalecer a grupos de medianos empresarios. Otros invitaron a gentes humildes a fundar pueblos para enlazar la mano de obra que aprovecharían las nuevas haciendas ${ }^{53}$.

La ruta de la colonización antioqueña hacia el sur, es definida por Tovar como un proceso que se adecua a los cambios experimentados por la sociedad colombiana en el siglo XIX. En este punto, establece dos características, que matizan su propuesta respecto al modelo de colonización de Parsons, pero no logra distanciarse totalmente. En la primera, define las concesiones de tierra como el elemento ordenador de la colonización, elemento que no está presente en las otras regiones de Colombia. Esta particularidad se presenta espacialmente en la zona comprendida entre Rionegro y Manizales. Temporalmente se puede ubicar en la primera mitad del siglo XIX:

[...] Las concesiones impulsaron la fundación de pueblos que valorizaron las tierras y controlaron la caótica penetración de los colonos. Los pueblos, en las concesiones, fueron espacios de equilibrio jurídico y factores de legitimación de la propiedad de los grandes concesionarios. Los colonos intentaron apoderarse del dominio político del municipio para disputarle a estos empresarios el derecho a la tierra [...] concesionarios y colonos en Antioquia, y colonos y peticionarios en el Tolima, promovieron el establecimiento de estas aldeas dónde buscar principios de acuerdo sobre el derecho a la propiedad que se cuestionaba ${ }^{54}$.

La segunda característica se ubica espacialmente en el territorio del Gran Cauca. Temporalmente corresponde a la segunda mitad del siglo XIX. Se distingue de la anterior

\footnotetext{
${ }^{51}$ Ibídem, 77-79.

${ }^{52}$ Catherine LeGrand, Colonización y protesta campesina en Colombia, 1850-1950 (Bogotá: Centro Editorial de la Universidad Nacional de Colombia, 1988).

${ }^{53}$ Tovar, Que nos tengan, 79, 80, 82.

${ }^{54}$ Ibídem, 80.
} 
porque la colonización dirigida por concesionarios empieza a perder importancia hasta diluirse en el norte del Valle del Cauca. Esta disgregación no se da "por decisión de los empresarios, sino por razones propias del desarrollo de la sociedad colombiana". Este proceso es abordado por Tovar diferenciando dos subregiones. La primera comprende la zona ubicada entre el río Chinchiná y el río la vieja, área calificada como de transición,

[...] en donde no era una sola empresa la dueña de los baldíos para afrontar los colonos, sino que la tierra era de quien primero llegara y supiera realizar los tres pasos siguientes a la ocupación: petición de adjudicación, deslinde y adjudicación como propiedad definitiva. No bastaba con llegar a unos baldíos y trabajar en ellos, era necesario recorrer un camino jurídico en el que cada paso tenía unos riesgos y unos costos. Entre paso y paso podían surgir obstáculos. A la conquista de hecho sucedía la conquista de derechos ${ }^{55}$.

La segunda subregión corresponde al actual departamento del Quindío. El modelo propuesto por Tovar no es muy claro. En esta región se combina el viejo sistema de concesiones y las expectativas de ganancias. La versión dada sobre la compañía Burila, empresa escogida para demostrar sus planteamientos, es muy general y no logra una interpretación diferente a la conocida tradicionalmente. El Departamento del Valle del Cauca solamente es mencionado de forma tangencial, como se indicó arriba. En su jurisdicción la colonización antioqueña se diluyó.

La información utilizada por Tovar corresponde casi exclusivamente a literatura secundaria; evento paradójico, si tenemos en cuenta, que el autor utiliza en el resto de la obra una profusa documentación del Archivo General de la Nación. Este error lo lleva a desconocer las particularidades de los procesos de frontera y de colonización que estudia y lo conduce a la apropiación mecánicamente del modelo de Parsons.

\section{Los estudios regionales}

\section{a. Violencia y colonización en el Valle del Cauca}

Urbano Campo no cita a Parsons, tampoco aborda los antecedentes del proceso de colonización en el departamento del Valle del Cauca ${ }^{56}$. Su obra es excepcional dentro del grupo de defensores - continuadores del modelo parsoniano, porque es fuente obligada de otros estudios que lo retoman y le dan continuidad. El objetivo del autor es analizar las condiciones y circunstancias

\footnotetext{
${ }^{55}$ Ibídem, 80, 81 y 102. La disputa por el control de la tierra en esta zona es asociada por Tovar a la ausencia de grandes concesiones, lo que permite que muchos colonos y nuevas elites compitan por la comercialización de la frontera. Así tenemos a medianos propietarios que ven la posibilidad de enriquecerse, a promotores o empresarios de colonización, que impulsan la ocupación de sus propiedades fomentando la migración de colonizadores mediante engaños, para luego obligarlos a comprar los lotes que habían ocupado.

${ }^{56}$ Urbano Campo, Urbanización y violencia en el Valle (Bogotá: Ediciones el Armadillo, 1980).
} 
que generaron en el Valle del Cauca, el paso de un poblamiento agrario a un proceso de urbanización moderno; transición ocurrida durante las décadas de los años 40 y 50 del siglo pasado. La causa de esta transformación es la guerra interna, económica y de clases, denominada con el nombre de "La Violencia". Guerra agenciada por los Estados Unidos, nuevo líder mundial, en el marco de su política de guerra fría contra el comunismo internacional ${ }^{57}$.

En el capítulo dos, Urbano efectúa una descripción global de la colonización en ésta región del país: define las rutas de penetración de los colonos, reseña la procedencia de los nuevos pobladores y las causas que originaron su migración, constata la conformación de una economía de subsistencia, menciona la fundación de los nuevos poblados, destaca la importancia del café y señala el proceso de concentración de la tierra, que se operara en la zona ${ }^{58}$. El tercer capítulo, está dedicado a las actividades de los empresarios territoriales Vicente E., Leocadio Salazar y don Carlos, personajes descalificados con términos peyorativos: "aventurero", "buscavida", "fundador pirata", "vivo", "rompe latifundios", "rompe colonos", "usurero de pueblo" y "financista de especulaciones y expoliaciones rurales" $"$.

En el estudio de las actividades empresariales sobresale el caso de Leocadio Salazar como fundador de pueblos, promotor de compañías de compra-venta de tierras, constructor de caminos e impulsor de procesos de colonización espontánea con prostitutas, expresidiarios y adolescentes solteros. El autor resalta la capacidad de éste empresario para entablar litigios por tierras baldías y asocia la expulsión de pequeños propietarios y varias masacres ocurridas durante la violencia al desarrollo de estos pleitos ${ }^{60}$. A pesar de la debilidad en la evidencia para verificar las hipótesis planteadas, el trabajo de Urbano Campo es importante porque reseña la llegada al Valle del Cauca de colonos de diferentes regiones del país y sugiere que la penetración de las vertientes cordilleranas se realizó por diferentes rutas ${ }^{61}$.

Los trabajos de Darío Betancourt ${ }^{62}$, inclusive los realizados en compañía con Martha García, no reflejan la consolidación de un proyecto de investigación que paulatinamente devele las particularidades de la colonización de vertiente en el Valle del Cauca. Por el contrario, pueden calificarse como versiones recicladas de la ponencia presentada en el V Congreso Nacional de Historia de Colombia celebrado en Armenia en 1986, a la que le suprimen algunos apartes, le agregan nuevos datos o simplemente cambian el orden de los párrafos ${ }^{63}$. Con excepción del

\footnotetext{
${ }^{57}$ Ibídem, 9-16.

${ }^{58}$ Ibídem, 17-19.

${ }^{59}$ Ibídem, 24-54.

${ }^{60} \mathrm{Ibídem}, 28-52$. Además notas no. 13 y 14, 133 .

${ }^{61}$ Planteamientos que han pasado desapercibidos para la mayoría de los investigadores, quienes se apoyan en esta obra para sustentar sus hipótesis.

${ }^{62}$ Después de la redacción de este balance, Darío Betancourt publicó dos libros, Mediadores, rebuscadores, traquetos y narcos. Valle del Cauca, 1890 -1997 (Bogotá: Antropos, 1998) e Historia de Restrepo Valle (Cali: Imprenta Departamental, 1998). El contenido de estas obras no altera los argumentos que se exponen respecto a la producción académica de este autor.

${ }^{63}$ Es importante aclarar que en esta ponencia, Betancourt cita otra comunicación de su autoría, "Los 'Pájaros' en el Valle del Cauca. Colonización, café y violencia”, presentada en 1984, en el Centro Cultural Jorge Eliécer Gaitán de Santafé de Bogotá. Para este balance no fue posible consultar este material. Posiblemente, este escrito es la versión
} 
artículo, "La colonización antioqueña tardía y la fundación de pueblos en las cordilleras del Valle del Cauca (1900-1940)", el objetivo de sus escritos es analizar la Violencia de mediados del siglo XX en el Valle del Cauca ${ }^{64}$.

Betancourt no hace referencias a Parsons, ni en las notas de pie de página, ni en la bibliografía; pero relaciona la ocupación de vertientes en el Valle del Cauca con los desplazamientos de antioqueños hacia el sur, que originan la fundación de Manizales, Armenia, Circasia y Montenegro. La migración procedente del Tolima, Caldas, Cauca, Boyacá y Nariño, es asociada a tres causas. La primera es el clima de paz reinante en el territorio nacional después de la guerra de los Mil Días. Este acontecimiento posibilitó la liberación de los miembros de los ejércitos en contienda, quienes se dedicaron al desbroce de la selva. La segunda es el empeño de los colonos en sembrar café en las tierras altas dejadas al margen por las empresas colonizadoras. El auge del cultivo de este producto es atribuido a la popularización del despulpador de manubrio. La tercera es la búsqueda de sepulcros indígenas, actividad que motiva el asentamiento de muchos guaqueros al comprarle mejoras a los colonos y establecerse como finqueros ${ }^{65}$.

La ausencia de referencias directas a la obra de Parsons no impide a Betancourt rechazar la versión rosa de la colonización antioqueña. De igual forma, la fundación de los nuevos poblados es atribuida a la valorización de las tierras de ladera y como ejemplo cita los casos de Restrepo y Sevilla. El único empresario territorial estudiado es Leocadio Salazar, pero el análisis de sus actividades es muy superficial. Sólo utiliza la información aportada por Urbano Campo sin someterla a un proceso crítico. En el texto prevalece la visión negativa de éste personaje que aparece originalmente en el libro, Urbanización y Violencia en el Valle ${ }^{66}$.

Un aspecto relevante en los escritos de Betancourt es el estudio de los conflictos agrarios ocurridos en el departamento del Valle del Cauca en el periodo 1910 - 1945. Estos

inicial del autor sobre la colonización de vertiente en el Valle del Cauca y no el texto leído en la capital del departamento del Quindío.

${ }^{64}$ Darío Betancourt "De los 'Pájaros' a las cuadrillas del norte del Valle”, en, Instituto Colombiano para el Fomento de la Educación Superior. Memorias del Quinto Congreso de Historia de Colombia, Armenia, 1986 (Bogotá: ICFES, 1986), 419; Darío Betancourt y Martha García, Matones y cuadrilleros. Origen y evolución de la violencia en el occidente colombiano, (Bogotá: Tercer Mundo Editores - Universidad Nacional de Colombia, Instituto de Estudios Políticos y Relaciones Internacionales, 1990),19, 23, 24, 25, 35, 36 y ss. En la ponencia "El conflicto agrario y la violencia partidista de los cincuenta en el Valle, 1920 -1957. (Policía, Política y Pájaros)”, presentada en el VI Congreso de Historia de Colombia, Ibagué, 1987, Betancourt no formula un objetivo específico. Sin embargo, la similitud de este escrito con el presentado en Armenia, permite suponer que el autor tenía el mismo objetivo. En adelante las ponencias de los Congresos de Historia de Colombia se citarán solamente con el nombre de la ciudad donde se realizó el evento y con el año.

${ }^{65}$ Betancourt, Armenia (1986), 421 y 423; Betancourt, Ibagué (1987), 1. En esta ponencia el autor no reseña el arribo de colonos procedentes del Tolima, Cauca, Caldas, Boyacá y Nariño; Betancourt y García, Matones y cuadrilleros, 44, 46; Darío Betancourt y Martha García, "La colonización antioqueña tardía y la fundación de pueblos en las cordilleras del Valle del Cauca (1900-1940)", en Julián Arturo comp., Pobladores urbanos. Ciudades y espacios (Bogotá: Tercer Mundo Editores/ICAN/COLCULTURA, 1984), 123, 124.

${ }^{66}$ Betancourt, Armenia, (1987), 422; Ibagué, (1987), 4; Betancourt y García, Matones y cuadrilleros, 50; Betancourt y García., "La colonización", 126. 
enfrentamientos son asociados a la agitación social de los años veinte en Colombia. La escasez de tierras en la parte plana del departamento generó una disputa entre tenderos, comerciantes y hacendados por la apropiación de los terrenos baldíos en las vertientes cordilleranas. Estos actores reclamaban sus derechos de propiedad sobre las tierras públicas con diferentes recursos: exhibían antiguos títulos coloniales, creaban empresas colonizadoras, compraban a precios irrisorios las parcelas de los colonos y, en algunos casos, utilizaban la violencia ${ }^{67}$. El resultado de este enfrentamiento se expresa en tres tipos de conflictos. El primero se suscita entre colonos y abogados, tenderos, comerciantes y extranjeros localizados en las ciudades de la parte plana del departamento, quienes ubicaban los lugares donde los colonizadores establecían sus mejoras $\mathrm{y}$, de inmediato, gestionaban la adjudicación de estos terrenos alegando su calidad de baldíos ${ }^{68}$.

El segundo conflicto opone a hacendados y colonos. Los primeros por medio de juicios de deslinde intentan extender los límites de sus propiedades y abarcar las mejoras de los colonizadores ubicadas en terrenos baldíos. Al perder sus labranzas los colonizadores entrarían a formar parte de las haciendas en calidad de mano de obra. Como ejemplos el autor analiza los casos de las haciendas Tapias y Salento en jurisdicción del municipio de la Cumbre ${ }^{69}$. El tercer conflicto se presenta entre colonos y empresas colonizadoras, como "Burila", "Barragán" y "Cuancua", cuyos socios reclaman la propiedad de terrenos baldíos con el fin de parcelarlos y venderlos ${ }^{70}$.

En conjunto los trabajos de Betancourt carecen de una revisión bibliográfica y de evidencia empírica suficiente para demostrar las hipótesis planteadas, a pesar los datos extraídos del Archivo General de la Nación, del Archivo de la Gobernación del Departamento del Valle del Cauca y de algunos periódicos de circulación regional, especialmente en los apartes dedicados a los puntos de partida de los nuevos pobladores, las causas que ocasionaron desplazamiento de los colonos, los motivos que generaron la fundación de los poblados y la participación de los empresarios y de las empresas colonizadoras en el proceso. Las "referencias" apenas perceptibles de la obra Parsons y la ausencia de un concepto de frontera explícito no impiden ubicar a Betancourt entre los defensores - continuadores del modelo.

Adolfo León Atehortúa analiza las violencias en el municipio de Trujillo, ubicado en el departamento del Valle del Cauca ${ }^{71}$. En los dos primeros capítulos estudia la colonización, fundación y consolidación socioeconómica de esta municipalidad, procesos asociados a la colonización antioqueña; particularidad que no oculta el arribo de colonos procedentes del Tolima, Cundinamarca, Boyacá y Cauca. En la obra el modelo de Parsons aparece

\footnotetext{
${ }^{67}$ Betancourt, Armenia (1987), 423; Ibagué (1987), 2; Betancourt y García, Matones y cuadrilleros, 47 Betancourt y García, "La colonización”, 127.

${ }^{68}$ Betancourt, Armenia (1987), 423, 424; Ibagué (1987), 2, 3; Betancourt y García., Matones y cuadrilleros, 47, 48 y 49; Betancourt y García, "La colonización", 127, 128 y 129.

${ }^{69}$ Betancourt, Armenia (1987), 424, 425; Ibagué, (1987), 3, 4; Betancourt y García, Matones y cuadrilleros, 49, 50; Betancourt y García, "La colonización”, 129.

${ }^{70}$ Betancourt, Armenia (1987), 421, 422, 425; Ibagué (1987), 4; Betancourt y García, Matones y cuadrilleros, 50; Betancourt y García, “La colonización”, 124, 126, 130.

71 Adolfo León Atehortúa, El poder y la sangre. Las historias de Trujillo (Valle) (Santafé de Bogotá: CINEP/Pontificia Universidad Javeriana - Seccional Cali, 1995).
} 
implícitamente y no hay mayores referencias. Sin embargo, Atehortúa retoma las rutas de colonización que plantea y las describe épica y apologéticamente:

[...] comenzaron su marcha en las lejanas tierras de la Concesión Echeverry [...] era costumbre detenerse en Fredonia o en Venecia y pasar el río Cauca hasta llegar a Jericó o a Puerto Rico. Allí se reunían con las familias procedentes de Concordia y Tarso. Descansaban en Támesis, Jardín o Valparaíso, y caían a Caramanta [...] los excedentes de población y la necesaria e incontenible búsqueda de nuevas fronteras, empujaban hacia el sur. Allí estaba Marmato, Supía y Riosucio que no ofrecían tampoco la atracción ni garantías deseadas [...] en la pausa más agradable del largo camino los antioqueños encontraban a la resucitada Anserma [...] al seguir por la montaña [...] encontraban a Risaralda, Santuario y Viterbo. Desde allí seguían los caminos que conducían a un sinnúmero de pueblos recién fundados: El Aguila, Ansermanuevo, El Cairo, Argelia, Versalles, Betania, hasta llegar a la tierra prometida [...] una segunda oleada procedía de Marinilla, Rionegro, Carmen de Viboral, Abejorral y Sonsón. Pasaron por Aguadas, Salamina, Palestina $[\ldots]^{72}$.

La fundación de Trujillo, conocido inicialmente con el nombre de Vernaza, es asociada a las actividades empresariales de Leocadio Salazar. La parte final del primer capítulo y la totalidad del segundo, están dedicadas al estudio de la conformación y consolidación socioeconómica del nuevo poblado, proceso articulado en torno a la economía cafetera. Atehortúa, estudia, además, los cambios político - administrativos de la nueva población. En su análisis logra entrelazar los desarrollos políticos a escala nacional, departamental y local ${ }^{73}$.

El autor utiliza fuentes de diverso orden para construir su versión de estos acontecimientos: literatura secundaria, periódicos de circulación nacional, regional y local, el Archivo General de la Nación, revistas y testimonios orales etc. Sin embargo, la descripción del proceso de colonización no es sustentada empíricamente y las extensas citas de los testimonios orales, han sido editadas en función de estilo. Este recurso les resta fuerza argumentativa. Tampoco analiza las actividades empresariales de Leocadio Salazar. En el relato predomina una visión negativa de este personaje inspirada en la obra de Urbano Campo, Urbanización y Violencia en el Valle.

Estos inconvenientes son producto de la ausencia de un problema planteado explícitamente sobre la colonización en el municipio de Trujillo. Como el objetivo del libro son las violencias, Atehortúa se limita a elaborar un contexto general de los procesos de ocupación de la zona. La ausencia de trabajos previos relativos a esta temática lo llevan a aceptar el modelo de Parsons, prototipo utilizado sin una alusión abierta a la obra de este geógrafo norteamericano y, adornado con un relato de tintes apologéticos. Este hilo narrativo se complementa con información fragmentada procedente de diversas fuentes y con testimonios orales. De esta manera, el autor soluciona el problema de investigaciones previas pero su libro entra a la galería de los defensores - continuadores del modelo parsoniano.

\footnotetext{
${ }^{72}$ Ibídem, 21-23.

${ }^{73}$ Ibídem, 29-38 y 35-75.
} 


\section{b. La obra de Jacques Aprile}

Jacques Aprile es el único investigador que ha procurado profundizar en el análisis del proceso de poblamiento de vertiente en el Departamento del Valle del Cauca. El resultado de sus investigaciones se encuentra publicado en tres libros, dos de ellos realizados con Gilma Mosquera Torres y, en un artículo, "Sevilla. El proceso de colonización y fundación", editado por la Revista de Integración Vallecaucana. Este autor tiene, además, un trabajo inédito titulado, "Conflictos Agrarios en el Valle. 1900 - 1940. Los antecedentes de la Violencia"; para efectos de este balance no fue posible consultar los dos últimos trabajos ${ }^{74}$.

En su primer libro Aprile y Mosquera estudian la ciudad colombiana contemporánea y el rápido proceso de urbanización del país. La obra está dividida en dos partes. En la inicial, analizan la primera implantación urbana realizada por los españoles en Colombia y consignan algunos apuntes referentes al proceso de poblamiento acaecido en el país entre 1850 y $1930-1950^{75}$.

Los apuntes referentes al poblamiento de vertiente en el Valle del Cauca se encuentran consignados en la segunda parte. Los autores, con base en Parsons, asocian este proceso a la colonización antioqueña, hecho que llaman "éxodo Antioqueño". Lo atribuyen a tres factores: el agotamiento o cansancio de la tierra que motivó desde el siglo XVIII la salida de cultivadores en la búsqueda de suelos fértiles; las altas tasas demográficas de los antioqueños, que generan la expulsión de excedentes de población y el cultivo del café. Como causas secundarias citan la existencia de caminos interregionales tradicionales que atraviesan la zona cafetera y la unen con las vías de exportación - importación, y la condición de baldíos de los terrenos de ladera aptos para el cultivo, despreciados durante dos siglos por las grandes haciendas ubicadas en los altiplanos y en los valles interandinos. En las conclusiones cuestionan el mito antioqueño por sus connotaciones retrógradas y clasistas $\mathrm{y}$, reconocen procesos colonizadores en diferentes regiones colombianas ${ }^{76}$.

Los autores construyen una tipología sociológica de los colonos -¿Quiénes eran?- y establecen la relación entre colonización y fundaciones. Este vínculo les permite realizar un modelo general de una fundación, compuesto por trece etapas cronológicamente determinadas y elaborar una secuencia de diecinueve pasos de un proceso de colonización agraria que evoluciona de una fase inicial caracterizada por una poblamiento disperso, hacia una formación urbana. Con base en estos modelos Aprile y Mosquera analizan diferentes tipos de fundaciones

\footnotetext{
${ }^{74}$ Jacques Aprile-Gniset y Gilma Mosquera, Dos ensayos sobre la ciudad colombiana. (Cali: Universidad del Valle, 1978); Jacques Aprile y Gilma Mosquera, Clases y segregación de barrios, (Cali: Universidad del Valle, 1984) y Jacques Aprile-Gniset, La ciudad colombiana. Siglo XIX y siglo XX (Bogotá: Banco Popular, 1992).

75 Aprile-Gniset y Mosquera, Dos ensayos 7, 69. Una versión preliminar de este trabajo fue publicada en enero de 1977 en el no. 2 de la Revista de la Facultad de Arquitectura de la Universidad Nacional, sede Medellín.

${ }^{76}$ Ibídem, 90, 91 y 166, 167.
} 
y establecen una tipología general integrada por: fundaciones espontáneas generadas por colonizaciones agrícolas, fundaciones especulativas, fundaciones asociadas a la construcción del Ferrocarril del Pacífico y fundaciones impulsadas o apoyadas por la Iglesia católica ${ }^{77}$.

Esta metodología les impide abordar la colonización de vertiente en el Valle del Cauca como una totalidad. En su lugar emerge la idea de un proceso fragmentado, integrado por una serie de estudios de caso, desligados entre sí y planteados para verificar la pertinencia de la tipología de fundaciones propuesta. En algunos apartes se encuentran referencias contradictorias a determinadas fundaciones y como ejemplos se pueden citar los casos de la La Habana, La Magdalena y Costa Rica.

En su segundo estudio, Aprile y Mosquera desarrollan la misma metodología de su primer libro. Decantan el modelo general de una fundación y la secuencia de diecinueve pasos del proceso de colonización agraria y plantean un prototipo para el estudio del proceso de conformación y consolidación de las sociedades que surgen de la colonización de vertiente en el Valle del Cauca. No obstante, es necesario someter su propuesta a mayores exigencias de verificación, pues fue construida con base en fuentes orales y bibliografía secundaria, especialmente monografías o historias locales, con poca información sobre la dinámica social de los procesos colonizadores ocurridos en esta región del país.

En la primera parte del libro, los autores dedican el capítulo 4 a la colonización de vertiente en el Valle del Cauca, proceso asociado a la tercera ola de la colonización antioqueña, desarrollada a finales del siglo XIX y las primeras décadas de la centuria del XX, con base en Parsons. Los autores, solamente describen superficialmente la ruta de penetración de los colonos a las estribaciones cordilleranas ${ }^{78}$. El resto del capítulo está dedicado al desarrollo de un modelo explicativo, compuesto por cinco fases, de la conformación de las sociedades que surgen de este proceso. Las primeras tres fases: "hábitat disperso", "nuclearización y homogeneidad" y "diferenciación individual", comprenden el arribo de los colonos, el desbroce de la selva y la siembra de los primeros cultivos de subsistencia. Estos sembrados se diversifican hacia especies comerciales, obligan a la construcción de caminos hacia los centros de consumo y al establecimiento de un mercado cercano, que da pie a la fundación de un nuevo poblado y a la diferenciación de los roles socioeconómicos de los colonizadores: de agricultores pasan a desempeñar oficios de barberos, tenderos, sastres y empresarios de industrias familiares de cobertura local.

La cuarta y la quinta fase son asociadas a la consolidación de la economía cafetera y su ligazón con mercados nacionales, regionales y mundiales y, a los efectos de la violencia de mediados del siglo pasado sobre las sociedades que surgen de la colonización de ladera. El afianzamiento del café desliga al poblado de su entorno y destruye la fusión producción-mercado localalojamiento, que se tenía en las fases anteriores. Se origina el paso de una economía "aislada",

\footnotetext{
${ }_{78}^{77}$ Ibídem, 92-98.

${ }^{78}$ Aprile-Gniset y Mosquera, Clases y segregación, 19. Además, véase la nota de pie de página número 10 que se encuentra en la página 58 .
} 
"sencilla" y "autosuficiente", a una economía regida por las leyes del mercado donde intervienen "recolectores e intermediarios, especuladores, prestamistas, transportadores y vendedores especializados". El resultado de estas actividades es la expulsión de los colonos o la venta sus parcelas. Estos colonizadores migran hacia otras zonas de colonización o se radican en las áreas urbanas como artesanos, pequeños comerciantes o jornaleros agrícolas. Los nuevos propietarios consolidan una clase media rural, compuesta por comerciantes y exportadores del grano, por medianos propietarios de fincas, por dueños de haciendas cafeteras residentes en la parte plana y por comerciantes. Las áreas urbanas crecen físicamente, se constituyen nuevos barrios, se construye una infraestructura de servicios públicos y escolares. En la zona rural, se observa la construcción de una infraestructura destinada a modernizar el proceso de beneficio del cafe ${ }^{79}$.

En su último trabajo publicado, Aprile, realiza una interpretación histórica de la formación de los núcleos urbanos en Colombia. En la consecución de este propósito recoge gran parte de los planteamientos desarrollados en su primer libro, Dos Ensayos sobre la Ciudad Colombiana. El estudio de la colonización de vertiente se encuentra en el capítulo VII del segundo volumen y en algunos apuntes efectuados en el primer capítulo titulado "Generalidades". El autor orienta su análisis hacia auscultar la fundación de nuevas poblaciones en el Valle del Cauca. Espacialmente su objeto de estudio no es definido por la jurisdicción territorial del departamento, sino por el valle geográfico del río Cauca y sus áreas circunvecinas. En el libro encontramos, además de las fundaciones de vertiente, los casos de Pradera, Florida, Corinto, Miranda; de los pueblos originados por manumisos (Puerto Tejada, Padilla y Villarica) y los caseríos de mercadeo ubicados en el piedemonte de los Farallones de Cali, (Cordillera Occidental), entre Dapa y Timba, originados por migraciones de indígenas paeces y guambianos $^{80}$.

Aprile reconstruye parcialmente la colonización de vertiente en el Valle del Cauca, aborda su análisis con estudios de caso, utilizados como los modelos de fundación que propone, sin establecer un orden cronológico, sin identificar relaciones entre ellos y sin un hilo conductor en la trama narrativa, que permita al lector construir una visión totalizadora del proceso. Las fuentes utilizadas comprenden testimonios orales, memorias de colonos pioneros y de prohombres de estos municipios, en muchos casos inéditas, monografías locales y documentos de archivos notariales y del fondo Baldíos del Archivo General de la Nación.

El primer modelo de fundación es definido como de "auto - generación dialéctica". Es autónomo y $\sin$ interferencias externas, producto de un propósito común entre los colonizadores, donde media la acción solidaria y las posturas altruistas y democráticas. La fraternidad inicial no resiste la creciente división del trabajo y se desvanece definitivamente con la estructuración clasista. Como ejemplo cita los casos de Versalles, Argelia, Sevilla, Daríen y Ceilán. La solidaridad entre los colonos no es óbice para que la fundación de los dos últimos

\footnotetext{
${ }^{79}$ Ibídem, 31, 33 y 36 - 38.

${ }^{80}$ Aprile-Gniset. La ciudad, 5- 9, 298 - 313 y 332 - 334.
} 
poblados citados se efectúe en medio de conflictos entre los colonizadores y los propietarios de la zona ${ }^{81}$.

El segundo modelo corresponde a las fundaciones para colonos y no por colonos. Estas poblaciones son fruto de actividades especulativas y mercantilistas. Los antecedentes de estas operaciones tienen su origen en los negocios de especulación realizados en el siglo XIX por importadores y exportadores extranjeros, por grandes comerciantes, por hacendados dedicados al comercio de exportación y por negociantes indígenas, quienes conforman hacia 1880 una clase dirigente regional, fundadora de poblaciones con propósitos doblemente especulativos: centralizar y comercializar su producción agropecuaria y mantener una reserva de mano de obra estable cerca de su propiedad. Además, sacan provecho de la venta de lotes y solares urbanos y regalan los terrenos para la iglesia, la alcaldía, el cementerio y las escuelas públicas ${ }^{82}$.

Estas fundaciones se realizaron inicialmente en el valle geográfico del Río Cauca y posteriormente en el piedemonte cordillerano. Aprile estudia los casos de Pradera, Corinto, y Miranda. Respecto al poblamiento de vertiente en el Departamento del Valle del Cauca, aborda el caso de Restrepo, ubicado en la cordillera Occidental. Su impulsor fue el mismo hacendado que propició la fundación de Miranda en el Departamento del Cauca. Estos poblados cuentan con un diseño urbanístico imponente que en la práctica no se cumple ${ }^{83}$. Los casos anteriores son matizados con el estudio de La Marina, La Primavera, Bitaco, La Habana, La Magdalena y Costa Rica, pequeños villorrios ubicados en el piedemonte, colindantes con grandes haciendas ganaderas de la parte plana. El conflicto latifundio - minifundio obliga al hacendado a fundar un poblado. Los objetivos de la erección de estas poblaciones es diferente y se determina por la problemática particular de cada lugar ${ }^{84}$.

El tercer modelo fundacional propuesto por Aprile, atañe a los pueblos carrileros para colonos. Surgen en el contexto de "colonizaciones populares" o espontáneas asociadas a la construcción de obras públicas de comunicación y al enfrentamiento del campesinado con los latifundistas. Como ejemplos cita los casos de Pavas, La Cumbre y Bitaco ubicados en la cordillera Occidental sobre la vía del Ferrocarril del Pacífico que une a Cali y a Buenaventura, pero solamente estudia el proceso en Bitaco. Para ello se basa en la versión planteada en el trabajo realizado en compañía con Gilma Mosquera, Dos Ensayos Sobre la Ciudad Colombiana ${ }^{85}$.

En el libro no queda claro si las fundaciones de Sevilla y Caicedonia pertenecen a los tres modelos de colonización descritos arriba, si son variantes de ellos o, si integran un cuarto modelo. El proceso fundacional de Sevilla es realizado por el interés de los colonos, "subversivos y librepensadores", de tener un "centro de cohesión, para 'formar sociedad". La erección de Caicedonia, es definida como la "máxima expresión técnica de la planificación

\footnotetext{
${ }^{81}$ Ibídem, 313, 314.

${ }^{82}$ Ibídem, 332.

${ }^{83}$ Ibídem, 335-337.

${ }^{84}$ Ibídem, 337-343.

${ }^{85}$ Ibídem, 343-346.
} 
urbanística" realizada por la colonización empresarial, concretamente por la compañía Burila; cuyas actividades estudia en varios apartes del capítulo, sin realizar un análisis minucioso de sus actividades, solo apreciaciones generales sin sustentación empírica y con errores en la información utilizada para sustentar sus planteamientos ${ }^{86}$.

Una situación similar a la de Sevilla y Caicedonia se presenta con la fundación de Argelia, El Aguila, El Billar, El Cairo, Darién, Restrepo y Versalles. Estas poblaciones surgen por la llegada de colonos procedentes de Antioquia, Caldas y el Quindío en la búsqueda de sepulcros indígenas. Sin embargo, no define si estos casos pertenecen a un cuarto modelo de fundación o son una variante de las fundaciones colectivas y solidarias reseñadas en el primer arquetipo ${ }^{87}$. Es importante subrayar la utilización de un lenguaje ofensivo y descalificador en los apartes dedicados a los empresarios territoriales: "pícaros", "estafadores", "parásitos", epítetos que velan el rol de estos personajes en el proceso de colonización de vertiente en el Valle del Cauca.

Los aportes más importantes de Aprile y Mosquera, como defensores - continuadores de Parsons, son los modelos que proponen para explicar la fundación de nuevas poblaciones y la presentación de nuevos datos que contribuyen a llenar los vacíos dejados por el geógrafo norteamericano.

\section{c. Otros estudios regionales}

José María Rojas y Luis Carlos Castillo describen someramente la colonización de Barragán, Tenerife y la parte montañosa de los municipios de Pradera y Florida, ocupada por indígenas paeces que huían del pago del terraje ${ }^{88}$. La colonización de esta zona es asociada a la colonización antioqueña, proceso definido como causa motivadora de la creación del departamento del Valle del Cauca, concebido en calidad de mecanismo para contener la avanzada antioqueña hacia el sur. Lamentablemente, no profundizan ni sustentan empíricamente este planteamiento ${ }^{89}$.

Barragán y Tenerife son definidos como los dos últimos puntos de la colonización antioqueña hacia el sur. Asimismo, los autores plantean una ruptura respecto a los esquemas tradicionales de colonización, asociados al café, producto que impulsa la apertura de nuevos territorios. Proponen como alternativa, el concepto de colonización de tierras frías, por encima de los 2.700

\footnotetext{
${ }^{86}$ Ibídem, 346. Los apuntes sobre la Compañía Burila se encuentran en las páginas: 156-160; 318-327.

${ }^{87}$ Ibídem, 314. Argelia, Versalles y Darién también son citados en las fundaciones solidarias.

${ }^{88}$ José María Rojas y Luis Carlos Castillo, Poder local y recomposición campesina (Cali: Cidse/Universidad del Valle/Fondo DRI, 1991).

${ }^{89}$ Ibídem, 47-49, 85- 99.
} 
metros sobre el nivel del mar. Empero, no articulan este concepto a la colonización en el Valle del $\mathrm{Cauca}^{90}$.

Oscar Almario dedica un capítulo de su libro a la colonización antioqueña en el Valle del Cauca $^{91}$. Divide este proceso en dos periodos. El primero ocurre en la segunda mitad del siglo XIX y se caracteriza por un poblamiento disperso en las vertientes. El segundo se inicia a finales de la centuria pasada y se extiende hasta las primeras décadas del siglo XX. Se distingue por su nuclearización. El autor, no construye una imagen global de este proceso, solamente realiza menciones parciales del mismo, inspiradas en literatura secundaria. Señala el avance de los colonos por las cordilleras evitando a los propietarios de la zona plana, sostiene que la colonización fue más fuerte en la cordillera Occidental respecto a la Central, reseña la recuperación económica de Roldanillo, La Unión y Toro por la presencia de los colonizadores y describe superficialmente el caso de la Compañía Burila y la fundación de Caicedonia ${ }^{92}$.

\section{B. Los críticos - continuadores de la obra de James Parsons}

Marco Palacios acepta el modelo de Parsons y analiza la colonización antioqueña en dos capítulos $^{93}$. En el primero, reconoce en el "ethos del hacha, del esfuerzo y del logro", un ethos más igualitario, comparado con el predominante en las altiplanicies andinas y en la costa Atlántica. Empero, considera "imperdonable olvidar otros aspectos que fueron sustantivos para la conformación de aquella sociedad". Estas cuestiones lo alejan de Parsons en lo referente a la estructura agraria derivada de este proceso de poblamiento y lo llevan a defender la hipótesis del carácter no igualitario de la frontera antioqueña, producto del "acaparamiento de la tierra mediante métodos 'administrativos' [del] gamonalismo y [de] la violencia cotidiana". Para Palacios, Parsons:

[...] dejó la base más sólida para interpretar la colonización antioqueña, si bien destaca la importancia del latifundismo y de las formas de colonización de base capitalista, contribuye a nuestro juicio a reforzar la leyenda rosa porque apenas deja planteado el problema de la colonización campesina no oficial, o sea, la que no pasa por los registros oficiales y en cuanto a la estructura de las colonias agrarias confió demasiado en la letra de la ley y en la leyenda popular ${ }^{94}$.

\footnotetext{
${ }^{90}$ Ibídem, 39-46. Como ejemplos de otros procesos de colonización en tierras frías citan los casos de Salamina, Aguadas, Pácora y Marulanda.

${ }^{91}$ Oscar Almario G., La configuración moderna del Valle del Cauca, Colombia, 1850-1940. Espacio, poblamiento, poder y cultura (Cali: Cecan Editores, 1994).

${ }^{92}$ Ibídem, 134-141.

${ }^{93}$ Marco Palacios, El café en Colombia, 1850 - 1970. Una historia económica, social y politica, 2 edición (Bogotá: El Ancora/Colegio de México, 1983).

${ }^{94}$ Ibídem, 293-296.
} 
En el segundo capítulo, Palacios analiza los conflictos agrarios sostenidos por los colonos contra las empresas colonizadores, los grandes concesionarios de terrenos baldíos y entre colonos independientes. Muchos de estos casos son estudiados con base en un solo enfrentamiento o unos pocos litigios. No obstante, en su conjunto, representan una tipología de los enfrentamientos por el control de la tierra en distintas zonas de la colonización antioqueña ${ }^{95}$.

Keith Christie reconoce la existencia de varios procesos de colonización en el territorio colombiano, pero considera al antioqueño en el viejo Caldas, como "el más famoso, el mejor documentado y tal vez el más importante caso de colonización interna de la historia de Colombia" $"$. El autor acepta la ruta colonizadora propuesta por Parsons y se aleja de la "visión fascinante de unos campesinos descalzos y enruanados que lograron derrotar a los latifundistas en su búsqueda de tierra y seguridad en la frontera semitropical y escarpada". Este distanciamiento lo suman al grupo de críticos que defienden el carácter no igualitario de la frontera antioqueña ${ }^{97}$.

Christie se aleja del concepto de latifundista para explicar el carácter no igualitario de la frontera antioqueña y propone la noción de comerciante - terrateniente. Estos personajes:

[...] no sólo cultivaban las tierras de frontera para su propio beneficio, sino que poseían enormes concesiones de tierras, parte de las cuales eran consideradas por ellos como tierras para ser vendidas a los eventuales colonos con un pingüe provecho $^{98}$.

En los albores de la colonización antioqueña los comerciantes - terratenientes estaban radicados en Medellín. Después de 1850 fueron reemplazados por otros comerciantes - terratenientes radicados en Manizales ${ }^{99}$.

En su argumentación, Christie compara la estructura demográfica y económica de Antioquia con la del Gran Cauca. En el Cauca el crecimiento de la población fue alterado por los reclutamientos forzosos durante las guerras de independencia. Los efectos de esta perturbación se percibieron a lo largo de la primera mitad del siglo XIX. Los caucanos también padecieron inconvenientes económicos, derivados de las "severas tensiones raciales que perjudicaban la disciplina de trabajo", de la caída de la producción local de oro y de la incapacidad para "desarrollar y mantener una producción de exportación de gran escala a lo largo del siglo XIX" $"$.

\footnotetext{
${ }^{95}$ Ibídem, 293 - 340.

${ }^{96}$ Keith Christie, Oligarcas, campesinos y politica en Colombia (Bogotá: Universidad Nacional de Colombia, 1986), $23,24$.

${ }^{97}$ Ibídem, El viejo Caldas comprendía el territorio de los actuales departamentos de Caldas, Quindío y Risaralda, las dos últimas unidades políticas - administrativas le fueron separadas en la década de 1960.

${ }^{98}$ Ibídem, 24, 25.

${ }^{99}$ Ibídem.

${ }^{100}$ Ibídem, 27, 28.
} 
Antioquia no sufrió las alteraciones demográficas del Cauca. Económicamente la producción aurífera aumentó considerablemente en el siglo XVIII. A finales del periodo colonial las "oligarquías de comerciantes -mineros" tenían capital y gran experiencia comercial". En el siglo XIX las condiciones económicas siguen con un comportamiento favorable:

[...] era apenas natural que la sociedad antioqueña expandiera sus áreas de asentamiento hacia los pequeños y fértiles valles del sur, dadas las facilidades existentes: capital líquido, experiencia comercial y financiera en el comercio entre las provincias, una población en aumento y el acceso relativamente limitado a las haciendas de las familias del núcleo central en torno a Medellín ${ }^{101}$.

Estas características de la sociedad antioqueña se traducen en una actitud comercial hacia las concesiones de tierras. Esta disposición la estudia Christie para el caso de la elite de Medellín con las concesiones Villegas y Aranzazu. Su continuidad en la elite de Manizales, es abordada con el análisis de la compañía Burila, empresa fundada por caucanos pero controlada por los manizalitas. La tradición se extiende hasta el Valle del Cauca. Como ejemplo cita superficialmente las actividades de Leocadio Salazar. Esta visión conduce a Christie a esbozar la siguiente conclusión:

[...] la colonización de una parte de la frontera antioqueña fue llevada a cabo por un notable espíritu comercial. En este proceso, se estableció una importante fuente de ingresos para favorecer el fortalecimiento de algunas de las familias más prestantes de la región [...] Este aspecto de la colonización no puede considerarse significativamente "democrático". Pero tampoco implica en sí mismo una radical refutación de la tesis de "la frontera igualitaria"102.

Las críticas de Catherine LeGrand a la obra de Parsons se orientan en dos sentidos: polemiza con la tesis de la frontera igualitaria y cuestiona el argumento que define la colonización antioqueña como el único proceso de apertura de la frontera agraria en Colombia ${ }^{103}$. Este distanciamiento está fundamentado en el análisis de la dinámica del conflicto rural entre colonos - campesinos y empresarios territoriales en torno al control de las regiones fronterizas. El desplazamiento hacia las zonas de frontera fue motivado principalmente por el desarrollo del modelo agro - exportador. El resultado de la ocupación e incorporación de los nuevos territorios fue la concentración de la tierra en pocas manos y la presencia de un sinnúmero de conflictos sociales por el dominio de las tierras públicas en el campo colombiano antes de $1930^{104}$.

El estudio de los índices de adjudicación de terrenos baldíos y el análisis de los conflictos presentados por el control de las tierras públicas, le permiten a LeGrand elaborar una visión de conjunto de la apertura de la frontera agraria en Colombia, sin abordar las particularidades

\footnotetext{
${ }^{101}$ Ibídem, 29, 30.

${ }^{102}$ Ibídem, 31-36.

${ }^{103}$ LeGrand. Colonización y protesta.

${ }^{104}$ Ibídem, 13-17.
} 
regionales de este proceso. Este panorama le sirve para distanciarse de la tesis que pregona a la colonización antioqueña como el único proceso de frontera en el territorio colombiano y plantear un argumento alternativo:

En realidad, el movimiento antioqueño fue un episodio más bien excepcional en un proceso mucho más vasto del desarrollo de la frontera, que tuvo lugar en las tierras templadas y cálidas a finales del siglo XIX y comienzos del XX. Al pasarlo por alto, los historiadores han malentendido fundamentalmente el carácter de la expansión de la frontera en Colombia ${ }^{105}$.

Esta visión de conjunto sobre la frontera colombiana es uno de los aportes más significativos de LeGrand. También es uno de los aspectos más débiles de su obra, pues no logra dilucidar las particularidades regionales de los procesos de frontera. En el libro estos procesos, incluyendo el del norte del Suroccidente colombiano, quedan reducidos a referencias parciales sobre la adjudicación de baldíos, a la descripción general de las causas del desplazamiento hacia las zonas de frontera y a los conflictos suscitados entre colonos, hacendados y empresarios territoriales. Por ejemplo, la colonización de vertiente en el Valle del Cauca solamente es asociada a las solicitudes de adjudicación de terrenos baldíos por propietarios tradicionales de la región y por empresarios territoriales, a la apropiación ilegal de tierras públicas por hacendados que corrían sus linderos hasta las cimas de las cordilleras Central y Occidental, (como testimonio se cita el caso de Lisandro Caicedo) y, a los pedidos de concesión de baldíos por colonos pobres en las primeras décadas del presente siglo, quienes llegaban atraídos por el auge del cultivo del café y por la construcción del ferrocarril del Pacífico y del Muelle del Buenaventura $^{106}$

Queremos concluir este balance con dos obras de corte regional que pueden catalogarse como revisionistas y cuestionan el carácter hegemónico de la colonización antioqueña, pero la ausencia de un concepto de frontera explícito impide la elaboración de propuestas alternativas por estos autores. El primer trabajo, es el de Alonso Valencia, quien aborda someramente la colonización del Quindío, proceso asociado a la colonización antioqueña y estudiado sin un concepto explícito de frontera ${ }^{107}$. El autor únicamente señala las políticas desarrolladas por el Estado Soberano del Cauca para ocupar este territorio, inicialmente con colonias penales y después con inmigrantes procedentes de diversas regiones del país. El resultado de estos esfuerzos es el establecimiento incontrolado de cultivadores "que desarrollaron una economía de subsistencia en pequeñas parcelas [...] además, la débil presencia del Estado llevó a que se

\footnotetext{
${ }^{105}$ Ibídem, 17.

${ }^{106}$ Ibídem, 77, 82, 83.

${ }^{107}$ Alonso Valencia Llano, Empresarios y Políticos en el Estado Soberano del Cauca (Cali: Universidad del Valle Editorial de la Facultad de Humanidades, 1993). La lectura del capítulo deja la sensación de que Valencia define la frontera como un espacio vacío que se incorpora. La utilización del concepto frontera interior confirma esta apreciación. Por tanto en el texto subyace la noción de Turner.
} 
creara un sitio de inestabilidad política con alta criminalidad"108. Infortunadamente, el autor no presenta una evidencia empírica sólida para sustentar estos planteamientos.

La llegada de numerosos inmigrantes, posibilitó las actividades de los empresarios territoriales y la creación de empresas colonizadoras. En este punto, Valencia estudia con cierto detenimiento el caso de la compañía Burila, demuestra la importancia de las elites caucanas en la creación y control accionario de esta empresa. Finalmente, reseña la pésima administración de los terrenos baldíos por las autoridades del Gran Cauca y resalta la llegada de delincuentes y vagos antioqueños, pero no sustenta sus argumentos.

El segundo trabajo es la tesis de maestría de Olga Cadena Corrales, quien analiza el contexto histórico en el que se funda la Compañía Burila, estudia los conflictos suscitados por esta empresa y la define, como una sociedad anónima de tipo capitalista, fundada con dos objetivos: primero, valorizar y vender las tierras de su propiedad; segundo, concentrar capitales ante la escasez de medio circulante ${ }^{109}$. Esta investigación es realizada con base en documentos del Archivo General de la Nación, del Archivo de la Gobernación del Departamento de Caldas y con protocolos notariales. En su investigación, la autora logra la matizar y cuestionar el modelo de colonización de Parsons y demostrar la presencia de las elites caucanas en dicha compañía. No obstante, al igual que el trabajo de Alonso Valencia la ausencia de un concepto explícito de frontera y otro de colonización la priva de alcanzar mejores conclusiones ${ }^{110}$. En este trabajo de grado, como en la mayoría de las obras analizadas, la noción de frontera que subyace es la de un espacio vacío que se debe llenar. Nuevamente la concepción de Turner determina los rumbos de una investigación. La diferencia son los datos aportados por la investigadora.

\section{Conclusiones}

Después de analizar la forma como la historiografía colombiana se apropió y aplicó el modelo de colonización de Parsons podemos plantear las siguientes conclusiones:

1. El modelo de colonización propuesto por James Parsons no es pertinente para analizar los procesos de frontera y de colonización del norte del Suroccidente colombiano, actuales territorios de los departamentos de Quindío, Risaralda y estribaciones de las cordilleras Central y Occidental en el Valle del Cauca.

2. Como la propuesta de Parsons está inspirada en el modelo de Frederick Jackson Turner para el caso norteamericano, el prototipo de Turner tampoco es pertinente para el análisis de los procesos de frontera y de colonización del norte del Suroccidente colombiano.

\footnotetext{
${ }^{108}$ Ibídem, 52.

${ }^{109}$ Olga Cadena Corrales, Procesos de colonización en el Quindio: El caso Burila (Tesis de Posgrado en Historia, Universidad Nacional de Colombia, Bogotá, s.f.).

${ }^{110}$ Ibídem, 64-119.
} 
La pertinencia de la tesis y del modelo de Turner para analizar los procesos de frontera en América Latina, empezó a ser cuestionada desde la década de los años 20 del siglo pasado por Víctor Andrés Belaúnde y, a mediados del mismo siglo, por Silvio Zavala ${ }^{111}$. En las últimas décadas otros historiadores y científicos sociales se han sumado a estas voces discordantes ${ }^{112}$.

3. Al ser descartadas las propuestas de Turner y de Parsons, la historiografía colombiana se ve obligada a buscar otro modelo para estudiar los procesos de frontera y de colonización del norte del Suroccidente colombiano. Dicho modelo debe tener en cuenta las particularidades de los poblamientos efectuados durante el periodo de conquista y el periodo colonial, en las zonas aledañas a los territorios que son ocupados e incorporados.

En este sentido, proponemos como alternativa de análisis verificar el modelo denominado por Richard Morse como "Patrón de archipiélago". A diferencia de los Estados Unidos, donde la expansión hacia el Oeste se produjo en una sola nación y "en un solo sentido", mediante avanzadas acumulativas; en América Latina, los procesos de frontera ocurrieron en varias naciones y en diferentes direcciones. Después de las guerras de emancipación, en las primeras décadas del siglo XIX, se produjo una eclosión de estados nacionales y, por tanto, de procesos de delimitación territorial entre ellos; paralelamente al interior de los nuevos países, los espacios que habían permanecido "despoblados" durante el período colonial comenzaron a ser colonizados emergiendo un sinnúmero de fronteras. La ocupación de estas áreas se efectuó desde las antiguas fundaciones ocurridas bajo la dominación española, mediante un proceso de desplazamiento centrífugo, que posibilitó el llenado de las zonas que permanecían "desocupadas" entre dos núcleos urbanos ${ }^{113}$.

En el caso de los espacios vacíos o despoblados del norte del Suroccidente colombiano, la ocupación se efectuó desde las áreas pobladas durante la dominación española ubicadas en Antioquia, el valle del río Magdalena y el valle geográfico del río Cauca. Desde esta perspectiva, el proceso descrito por Parsons solamente corresponde a una de las rutas de penetración e incorporación de estos espacios, es fundamental analizar las rutas restantes para lograr una visión de conjunto.

\footnotetext{
111 Víctor Andrés Belaúnde, "The frontier in Hispanic America" y Silvio Zavala, "The frontiers of Hispanic America", en David J Weber y Jane M. Rausch, Where cultures meet: Frontiers in Latin American history (Wilmington, D. F: Jaguar Books on Latin America, 1994). Capítulos 4 y 5 respectivamente.

${ }^{112}$ Al respecto véase David Weber, "Turner, Los Boltonianos y las tierras de frontera", en Francisco de Solano y Salvador Bernabeu, coord., Estudios (nuevos y viejos) sobre la frontera (Madrid: Consejo Superior de Investigaciones Científicas, 1991), 61-84; Alfredo Jiménez, "La frontera en América: Observaciones, críticas y sugerencias", en María Justina Saravia Viejo y otros, eds., Entre Puebla y Sevilla. Estudios americanistas en homenaje al Dr. José Antonio Calderón Quijano (Sevilla: Escuela de Estudios Hispano Americanos/Universidad de Sevilla, 1997), 475-494.

${ }^{113}$ Hennessy, "The frontier", 17. El concepto de "archipiélago" fue propuesto para el caso brasileño por Richard Morse en su libro, The Bandeirantes, 30. En este caso ha sido retomado de la obra de Hennessy, autor que considera que es factible aplicarlo para el resto de América Latina.
} 
4. Para superar la apropiación pasiva y la aplicación mecánica del modelo de Parsons, la historiografía colombiana está obligada a diferenciar teóricamente los términos de colonización, frontera y poblamiento.

De igual forma, es importante "abandonar" la concepción geográfica de la frontera (espacios vacíos o despoblados que se ocupan) y explorar otras categorías que permiten abordar las dimensiones socioculturales de estos procesos. Así por ejemplo, para David Weber y Jane Rausch, la frontera es una zona de encuentro entre dos o más culturas; en otro artículo, Weber concluye que la

[...] frontera representa tanto un entorno humano como uno geográfico. Ya no se considera la frontera como una línea entre la "civilización y la barbarie" sino como una interacción entre dos culturas diferentes. La naturaleza de estas culturas interactivas - ambas culturas la del invasor y del invadido - se combinan con el entorno físico para producir una dinámica que es única en el tiempo y en el espacio $^{114}$.

Para José de Souza Martins, la frontera es el "lugar de la alteridad" y lo que caracteriza a la situación de frontera es el conflicto social, donde se "desencuentran diferentes temporalidades históricas, pues cada uno de los grupos está situado diversamente en el tiempo de la historia"115. La dimensión sociocultural permite un estudio más detallado de los actores de los procesos de frontera; por tanto, la construcción de nuevas agendas de investigación y el planteamiento de nuevas explicaciones a estos fenómenos.

Finalmente, superar la apropiación pasiva y la aplicación mecánica del modelo de Parsons no es tarea fácil. El desarrollo de las propuestas planteadas en las conclusiones exige años de investigación y es imposible predecir el resultado de este trabajo; por ahora podemos concluir con Isaialt Berlin, "No sabemos donde está el puerto; así pues, hay que seguir navegando".

\footnotetext{
${ }_{114}^{114}$ David Weber, "Turner, los Boltonianos, 84.

115 David Weber y Jane Rausch, "Where the cultures meet", xiv; José de Souza Martins, "O Tempo da Fronteira. Retorno à Controvérsia sobre o Tempo Histórico da Frente de Expansão e da Frente Pioneira”, Tempo Social 8, no. 1 (1996), 27, citado por Perla Zusman, "Representaciones, Imaginarios y Conceptos en torno a la Producción Material de las Fronteras. Reflexiones a partir del Debate Hebilla - Escamilla", Biblio 3W. Revista Bibliográfica de Geografía $y$ Ciencias Sociales, no. 149 (1999). El artículo fue bajado del portal en la web de la revista: http://www.ub.es/geocrit/b3w-149.htm.
} 


\section{Bibliografía}

Almario G., Oscar. La configuración moderna del Valle del Cauca, Colombia, 1850-1940. Espacio, poblamiento, poder y cultura. Cali: Cecan Editores, 1994.

Aprile-Gniset, Jacques. La ciudad colombiana. Siglo XIX y siglo XX. Bogotá: Banco Popular, 1992.

Aprile-Gniset, Jacques y Gilma Mosquera. Dos ensayos sobre la ciudad colombiana. Cali: Universidad del Valle, 1978.

Clases y segregación de barrios. Cali: Universidad del Valle, 1984.

Aróstegui, Julio. La investigación histórica: teoría y método. Barcelona: Editorial Crítica, 1995.

Atehortúa, Adolfo León. El poder y la sangre. Las historias de Trujillo (Valle). Santafé de Bogotá: CINEP/Pontificia Universidad Javeriana - Seccional Cali, 1995.

Belaúnde, Víctor Andrés. "The frontier in Hispanic America", en David J. Weber y Jane M. Rausch. Where cultures meet: Frontiers in Latin American history. Wilmington, D. F: Jaguar Books on Latin America, 1994.

Betancourt, Darío. "De los 'Pájaros' a las cuadrillas del norte del Valle". En: Memorias del Quinto Congreso de Historia de Colombia, Armenia, 1986, por Instituto Colombiano para el Fomento de la Educación Superior (ICFES). Bogotá: ICFES, 1986.

. "El conflicto agrario y la violencia partidista de los cincuenta en el Valle, 1920 1957. (Policía, Política y Pájaros)". Ponencia presentada en el VI Congreso de Historia de Colombia, Ibagué, 1987.

. Historia de Restrepo Valle. Cali: Imprenta Departamental, 1998.

. Mediadores, rebuscadores, traquetos y narcos. Valle del Cauca, 1890 -1997. Bogotá: Antropos, 1998.

Betancourt, Darío y Martha García. "La colonización antioqueña tardía y la fundación de pueblos en las cordilleras del Valle del Cauca (1900-1940)". En Pobladores urbanos. Ciudades y espacios, Julián Arturo, comp. Bogotá: Tercer Mundo Editores/ICAN/COLCULTURA, 1984.

. Matones y cuadrilleros. Origen y evolución de la violencia en el occidente colombiano. Bogotá: Tercer Mundo Editores/Universidad Nacional de Colombia/Instituto de Estudios Políticos y Relaciones Internacionales, 1990.

Cadena Corrales, Olga. Procesos de colonización en el Quindio: El caso Burila. Tesis de Posgrado en Historia, Universidad Nacional de Colombia, Bogotá, s.f.

Campo, Urbano. Urbanización y violencia en el Valle. Bogotá: Ediciones el Armadillo, 1980.

Christie, Keith. Oligarcas, campesinos y politica en Colombia. Bogotá: Universidad Nacional de Colombia, 1986.

De Souza Martins, José. "O Tempo da Fronteira. Retorno à Controvérsia sobre o Tempo Histórico da Frente de Expansão e da Frente Pioneira", Tempo Social 8, no. 1 (1996).

Fontana, Josep. Historia. Análisis del pasado y proyecto social. Barcelona: Editorial Crítica, 1982. 
Hennessy, Alistair. The frontier in Latin American history. Albuquerque: University the New Mexico Press, 1978.

Hofstadter, Richard. Los historiadores progresistas. Buenos Aires: Editorial Paidós, 1970.

Jaramillo, Roberto Luis. "La colonización antioqueña". En La historia de Antioquia, Jorge Orlando Melo, director general. 2a edición. Medellín: Editorial Presencia, 1991.

Jaramillo Uribe, Jaime. "Visión sintética de la tarea investigativa desarrollada sobre la región antioqueña". En Los estudios regionales en Colombia: El caso de Antioquia, Moises Melo y FAES, eds. Medellín: Fundación Antioqueña para los Estudios Sociales FAES/Biblioteca Colombiana de Ciencias Sociales, 1982. 1-15.

Jiménez, Alfredo. "La frontera en América: Observaciones, críticas y sugerencias". En Entre Puebla y Sevilla. Estudios americanistas en homenaje al Dr. José Antonio Calderón Quijano, María Justina Saravia Viejo y otros, eds. Sevilla: Escuela de Estudios Hispano Americanos/Universidad de Sevilla, 1997.

LeGrand, Catherine. Colonización y protesta campesina en Colombia, 1850-1950. Bogotá: Centro Editorial de la Universidad Nacional de Colombia, 1988.

"Colonización y Violencia en Colombia: Perspectivas y Debate". En El Agro y la Cuestión Social. Absalón Machado, comp. Bogotá: Tercer Mundo Editores/Banco Ganadero/Caja Agraria/Vecol, 1994.

López Toro, Álvaro. "Migración y cambio social en Antioquia durante el siglo XIX". En Ensayos sobre Demografía y Economía. Bogotá: Banco de la República, 1991.

Mandrini, Raul J. "Indios y Fronteras en el Area Pampeana (siglos XVI - XIX) Balance y Perspectivas", Anuario IEHS 1, no 7 (1992).

Morales Benítez, Otto. "La colonización antioqueña: Un Aspecto de la revolución económica de 1850". En La colonización antioqueña. Ficducal, comp. Manizales: Gobernación de Caldas, Biblioteca de autores caldenses, 1997.

Palacios, Marco. El café en Colombia, 1850-1970. Una historia económica, social y política. 2a edición. Bogotá: El Ancora/Colegio de México, 1983.

Parsons, James. The Antioqueño Colonization in Western Colombia. Berkeley: Universidad de California, 1949.

La colonización antioqueña. Medellín: Dirección Departamental de Educación de Antioquia, 1950.

. La colonización antioqueña en el occidente de Colombia, 2da ed. Bogotá: Banco de la República, 1961.

"Reminiscencias sobre 'La colonización antioqueña". En La colonización antioqueña, Ficducal, comp. Manizales: Gobernación de Caldas/Biblioteca de autores caldenses, 1997.

"Prefacio". La colonización antioqueña en el occidente de Colombia. Bogotá: Carlos Valencia Editores, 1979.

Robledo, Emilio. "Prólogo". En La colonización antioqueña en el occidente de Colombia, por James Parsons. 2da ed. Bogotá: Banco de la República, 1961.

Rojas, José María y Luis Carlos Castillo. Poder local y recomposición campesina. Cali: Cidse/Universidad del Valle/Fondo DRI, 1991. 
Saenz Obregón, Javier., Oscar Saldarriaga y Armando Ospina. Mirar la infancia: Pedagogía, Moral y Modernidad en Colombia, 1903-1946. Medellín: COLCIENCIAS/Foro Nacional por Colombia/Ediciones Universidad de los Andes/Editorial Universidad de Antioquia, 1997.

Santa, Eduardo. La colonización antioqueña. Una empresa de caminos. Bogotá: Tercer Mundo Editores, 1993.

Tovar Pinzón, Hermes. Que nos tengan en cuenta. Colonos, empresarios y aldeas: Colombia, 1800-1900. Bogotá: Colcultura, 1995.

Tovar Zambrano, Bernardo (compilador). La Historia al Final del Milenio. Ensayos de Historiografia Colombiana y Latinoamericana, 2 vol. Bogotá: Editorial Universidad Nacional, 1994.

Turner, Frederick J. "El Significado de la frontera en la historia americana". En La frontera en la historia americana. San José: Universidad Autónoma de Centro América, 1986.

Valencia Llano, Alonso. Empresarios y Politicos en el Estado Soberano del Cauca. Cali: Universidad del Valle/Editorial de la Facultad de Humanidades, 1993.

Weber, David. "Turner, Los Boltonianos y las tierras de frontera". En Estudios (nuevos y viejos) sobre la frontera, Francisco de Solano y Salvador Bernabeu, coord. Madrid: Consejo Superior de Investigaciones Científicas, 1991.

Weber, David J. y Jane M. Rausch. Where cultures meet: Frontiers in Latin American history. Wilmington, D. F: Jaguar Books on Latin America, 1994.

Zambrano, Fabio y Olivier Bernard. Ciudad y territorio. El proceso de poblamiento en Colombia. Bogotá: Academia de Historia de Bogotá/Instituto Francés de Estudios Andinos, 1993.

Zavala, Silvio. "The frontiers of Hispanic America". En Where cultures meet: Frontiers in Latin American history, David J. Weber y Jane M. Rausch, eds. Wilmington, D. F: Jaguar Books on Latin America, 1994.

Zusman, Perla. "Representaciones, Imaginarios y Conceptos en torno a la Producción Material de las Fronteras. Reflexiones a partir del Debate Hebilla-Escamilla", Biblio 3W. Revista Bibliográfica de Geografía y Ciencias Sociales, no. 149 (1999). 